\title{
Nudging and corporate environmental responsibility: A natural field experiment*
}

\author{
Leonardo Becchetti ${ }^{\dagger} \quad$ Francesco Salustri $^{\ddagger} \quad$ Pasquale Scaramozzino $^{\S}$
}

- This draft: 21 June 2020 -

\begin{abstract}
We devise a "nudging" natural field experiment to test the impact of a simple form of advertising on environmentally responsible products with/without the increase of the responsible product price. We find that the simple use of a small shelf poster explaining the importance of buying a green product (with/without a concurring price increase) generates significant changes in market shares for some of the product classes for both food and nonfood products. Part of the effect is generated by the reduced price elasticity of consumers to the poster-plus-price-increase treatment.
\end{abstract}

Keywords: nudging, environmental sustainability, consumer behavior, natural field experiment.

JEL Classification: C93 (Field experiments), D12 (Consumer economics: empirical analysis), M14 (Corporate culture; Social Responsibility), Q56 (Environment and Development; Sustainability)

\footnotetext{
${ }^{*}$ We thank Andrea Attar, Marco Battaglini, Sergio Beraldo, Giacomo Corneo, Marco Casari, Eloisa Campioni, Ciaran Driver, Matteo Galizzi, Werner Güth, Alberto Iozzi, Luca Lambertini, Maria Loureiro, Victor Murinde, Christine Oughton, Arsen Palestini, Vittorio Pelligra, Tommaso Reggiani, Matteo Rizzolli, François Salanie and Mariangela Zoli for their helpful suggestions and all participants of the 2017 RES PhD Meetings in London, the 2017 DeFiMS seminar at SOAS University of London, the 2017 DEDI Brown Bag Seminars at the University of Rome Tor Vergata, the 2017 LUISS Behavioral and Experimental Economics Workshop in Rome, the 2017 IEA Conference in Mexico City, the 2018 IAERE Conference in Turin, the CEIS Riccardo Faini Seminar in Rome in April 2018, and the 2018 WCERE Congress in Gothenburg. We are also grateful to the editor and two anonymous reviewers for their useful suggestions and comments. We thank all the staff of the Unicoop Firenze grocery store chain for their precious, indispensable support in arranging our experiment. The usual disclaimer applies.

${ }^{\dagger}$ Corresponding author. Dept. of Economics and Finance, University of Rome Tor Vergata, via Columbia, 2 - 00133 Rome. Email: becchetti@economia.uniroma2.it.

${ }^{\ddagger}$ Dept. of Economics and Finance, University of Rome Tor Vergata, and Nuffield Department of Population Health, University of Oxford. Current affiliation: Institute for Global Health, University College London. Email: f.salustri@ucl.ac.uk.

${ }^{{ }^{\hat{\beta}}}$ School of Finance and Management, SOAS University of London, and Dept. of Economics and Finance, University of Rome Tor Vergata. Email: ps6@soas.ac.uk.
} 


\section{Introduction}

The role of nudging as a new, original policy strategy to pursue socially optimal goals has attracted the attention of behavioral economics (Thaler and Sunstein, 2003, 2009). Traditionally, public economics relies on Pigouvian taxes to manage externalities such as environmental market failures (Atkinson and Stiglitz, 1980; Fisher, 1981). Other standard policy tools are quantity controls, which can be preferable when coordination is difficult to achieve (Weitzman, 1974). However, the actual implementation of these policies can be problematic: It may be difficult or too costly to measure the distance between private and social optimum and/or to enforce proper regulation. Furthermore, in globalized economies, a tax on the cost of pollution in one country may lead to delocalization and a "race to the bottom" by companies attempting to have the cheapest environmental production costs.

The recent literature on behavioral economics (Carlsson and Johansson-Stenman, 2012) and on green nudges (Schubert, 2016) has suggested that a libertarian paternalistic approach on the demand side, which slightly modifies the agents' choice architecture, may contribute to addressing the problem, with very limited costs for policymakers. This paper offers a novel contribution in this direction. We implement a natural field experiment (Harrison and List, 2004) to stimulate environmentally responsible behavior. The experiment is a typical green nudge, where a small poster was displayed in shops to remind consumers of the importance of purchasing an environmentally responsible product (Figure 1). The small poster was strategically positioned in a group of supermarkets, where it replaced the traditional price tag on the shelves.

We perform two variants of our experiment. In our base treatment, we simply display the small poster on the shelves. In our second treatment, we also increase the price of green products to test whether the nudging effect of the poster more than offsets the economic incentive to switch to non-green products.

The experiment attempts to examine whether nudging can be effective in affecting the choice of consumers. By considering a variety of products, the experiment can also indirectly provide insights into consumer preferences.

Our experiment is fully within the nudge category because, in contrast to incentive-based measures, we neither change the choice set (e.g., by banning or adding items) nor alter the set of 
incentives in the base treatment. The poster displayed in the shops simply reminds consumers of the importance of purchasing an environmentally sustainable product: It neither provides additional factual information nor offers rational, documented arguments to encourage the purchase of these products. By inviting customers to consider the consequences of their green choices on the environment and their well-being, the poster helps them overcome not just bounded rationality or cognitive bias but also bounded self-interest. The strategic placement of the poster and the emphasis on the importance of buying an environmentally responsible product are two features that are beyond the neutral information provision (Schubert, 2016).

In our second treatment, we increase the price of the green products to establish whether the effect of the nudge is sufficiently strong to counteract the economic substitution incentive, leading to an increase or to no change in demand where conventional choice theory would predict a decline. In this sense, we can compare the impact of the nudge on its own with its impact in a more adverse scenario, where economic incentives would elicit a switch in demand in the opposite direction.

The experiment also conforms to a paternalistic libertarian view because it aims at improving the environment and, through this, the well-being of individuals, consistently with the "libertarian paternalism" definition by Thaler and Sunstein $\underline{(2009)} \cdot{ }^{1}$

Our results show that consumers are receptive to our environmental labels and are willing to pay a premium for environmental sustainability. We find that the overall effect of the treatment is positive and statistically significant for food products. We also find a positive and significant effect on some non-food products that have no direct effect on personal health, which could reveal non-purely self-regarding preferences.

Our experimental findings contribute to the nudging literature and to the research on consumers' willingness to pay for environmentally responsible characteristics of a product. In Section $\underline{2}$, we discuss both strands of the literature.

The paper is divided into nine sections. In Section $\underline{2}$, we discuss how our experiment relates to the literature on nudging and libertarian paternalism. In Section $\underline{3}$, we present the experiment

\footnotetext{
${ }^{1}$ Notably, the concept of libertarian paternalism has evolved in a more subjective manner in the vision of the authors from policies "... selected with the goal of influencing the choices of affected parties in a way that will make those parties better off," where they intend by 'better off' to be "measured as objectively as possible" (and not always equating revealed preference with welfare) (Thaler and Sunstein, 2003) toward policies that seek "to influence choices in a way that will make choosers better off, as judged by themselves" (Thaler and Sunstein, 2009, see also the extensive discussion in Oliver, 2013; Rebonato, 2014; Hansen, 2016).
} 
design. In Section $\underline{4}$, we outline the methodology and define our testable hypotheses. In Section $\underline{5}$, we present descriptive evidence. In Section $\underline{6}$, we illustrate our econometric findings. In Section 7, we discuss our results. In Section $\underline{8}$, we suggest policy implications based on the results of the experiment. Section $\underline{9}$ concludes.

\section{Libertarian paternalism and nudging}

The debate on nudging, libertarian paternalism, and incentives has substantially evolved since the original seminal contribution by Thaler and Sunstein (2003). A heuristic definition holds that "a nudge is any factor that significantly alters the behavior of Humans, even though it would be ignored by Econs" (Thaler and Sunstein, 2003, p.8), where "Econs" basically refers to homo economicus. According to decision theory, the actions of a rational economic agent ought to depend solely on her choice set, preferences, and information in the state of the world. Hausman and Welch $(2010$, p.126) further stressed that nudges "are called for because of flaws in individual decision-making, and they work by making use of those flaws."

To qualify as a nudge, a policy should therefore not alter the choice set of the agents, significantly change their economic incentives, or rely on the provision of factual information and/or rational argumentation. Furthermore, the mechanism of the nudge should exploit the cognitive biases responsible for the departure from rational behavior. As lucidly defined by Hansen, "a nudge is a function of (1) any attempt at influencing people's judgment, choice or behavior in a predictable way that is (2) motivated because of cognitive boundaries, biases, routines and habits in individual and social decision-making posing barriers for people to perform rationally in their own declared self-interests and (3) which works by making use of those boundaries, biases, routines, and habits as integral parts of such attempts" (Hansen, 2019).

The concept of libertarian paternalism has evolved in a more subjective manner in the vision of Thaler and Sunstein, from policies "... selected with the goal of influencing the choices of affected parties in a way that will make those parties better off," where they intend by "better off" to be "measured as objectively as possible" (and not always equating revealed preference with welfare; Thaler and Sunstein, 2003) toward policies that seek "to influence choices in a way that will make choosers better off, as judged by themselves" (Thaler and Sunstein, 2009, see also the extensive 
discussion in Oliver, 2013; Rebonato, 2014; Hansen, 2016) ${ }_{-}^{2}$

Our experiment belongs to the class of "green nudging experiments" where, for instance, the "no" button answer to the question on printing the ATM receipt is moved strategically to the right (the side of the screen where attention is more easily focused and the previous button has been pushed) and a message in green appears on the screen during cashing operations reminding customers that not printing cash receipts is the "advised choice".

Another important element in the definition of our nudging experiment is related to agents' preference assumptions. As demonstrated in the literature, there is a strict connection between nudging and bounded rationality. In essence, nudging can produce significant changes in individuals' action by means of only slight frame changes when agents are "Humans" and not "Econs," that is, if they suffer from some forms of irrationality by which the nudge can modify their utility and their choices, even in absence of changes in monetary incentives in the choice set.

Our reference to the vote-with-the-wallet model suggests a slightly different story, where nudging does not necessarily need to exploit cognitive biases. Notably, the nudge represented by the label may have two effects that modify the choices of fully rational agents even without changing the monetary incentives of the choice set. First, the nudge can reinforce their beliefs on the environmentally sustainable features of the product, reducing informational asymmetries in this specific domain (see the model in Appendix B). Participants therefore choose the environmental product because they are more convinced than before of its characteristics that in turn satisfy the other-regarding component (if any) of their preferences. Second, the nudge can change subjects' expectations of the choice of the other subjects (see the model presented in Appendix B). This aspect is crucial in the vote-with-the-wallet multiplayer prisoner's dilemma structure. Notably, subjects may have reciprocity arguments (Rabin, 1993) that typically explain conditional cooperation in the aggregate and which make it rational for them to cooperate (buy the responsible product) if all other subjects (or a number of subjects consistent with their expectations) cooperate while making it rational to suspend cooperation if the share of cooperators decreases. In this perspective, our nudge may change subjects' expectations of the number of cooperators, inducing them to rationally buy the responsible product.

\footnotetext{
${ }^{2}$ Notably, the behavioral economics foundation of nudging has been subjected to criticisms on the grounds that government intervention can only be justified by market failures, and not by paternalism (Lusk, 2014; Just, 2017). Sugden $(2017,2018)$ takes issue with the claim that people want to be nudged and argues that Thaler and Sunstein are effectively using a model of akrasia, or failure of self-control. Sunstein (2018) presents a strong defense of the "libertarian paternalistic" approach by illustrating empirical evidence that individuals are often aware of self-control issues and are grateful to receive a nudge.
} 
We explicitly test this side assumption with an out-of-sample supplementary online survey and find that more than $80 \%$ of the respondents believe that the treatment affects the consumption choice of the other consumers (see Appendix $\underline{\mathrm{C}}$ for a detailed discussion of these findings). Consistently with the interpretation of nudges implied by our experiment, Sunstein (2015) and Hausman and Welch $\underline{(2010)}$ have argued that nudges do not necessarily trigger heuristics but may simply provide information. Examples mentioned in the literature are framing risks of medical treatments, reminding people vividly of the health consequences of smoking (Barton and GrüneYanoff, 2015), or placing a sign conveying that a river is dangerous to swim in (Sunstein, 2015). In this sense, our treatment passes the non-libertarian critique more easily than some nudges that deliberately rely on tricks (non-rational factors). On this point, Barton and Grüne-Yanoff (2015) remark that to remain libertarian, a nudge should be easy to avoid and not preclude any option.

In the literature, we observed a limited number of examples of experiments similar to ours and which show that although consumers attach value to ethical and environmental sourcing (Loureiro and Lotade, 2005; Becchetti et al., 2019), there is significant heterogeneity in their willingness to pay. Hudson et al. $(2012)$ analyze the capacity of a choice experiment to predict grocery store market shares and find that the level of control in the grocery store experiment and the choice of econometric model influence the capacity of the experiment to predict consumer responses. Hainmueller et al. $(2015)$ notice that sales in the United States of the two most popular coffees increased by almost $10 \%$ when they used a Fair Trade label compared with a generic placebo label. Demand for the higher priced coffee remained steady when its price was raised by $8 \%$, but demand for lower priced coffee was elastic because a $9 \%$ price increase led to a $30 \%$ decline in sales. Hiscox et al. (2011) measure consumers' willingness to pay with an experiment conducted on eBay and document that shoppers paid a $23 \%$ premium for Fair Trade labeled coffee.

Regarding the link between environmentally friendly labels and the perceived quality of products, Loureiro (2003) documents a negative relation when labels are attached to wines. Similar differences between high- and low-quality food and ecological labels are found by Van Doorn and

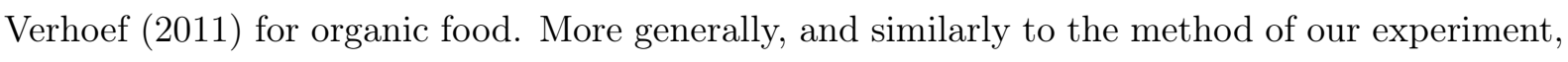
other contributions have shown that a reference to social norms has strong effects on pro-social behavior (Brekke et al., 2003; Griskevicius et al., 2008; Goldstein et al., 2008; Goldstein and Cialdini, 2009; Allcott, 2011). Studies that focus on the willingness to pay for responsible products 
have also documented that consumers are prepared to pay more for eco-labeled coffees (Sörqvist et al., 2013$).$

Our experiment relates to all the aforementioned strands of the literature (nudging, otherregarding preferences, willingness to pay experiments), but for the first time, it tests the effect of a shelf-poster treatment simultaneously applied to a wide range of green products. This novel feature allows us to formulate new research questions, such as on which of the treated products the treatment has significant effects. The empirical results of the paper show that the treatment has positive and significant effects on the market shares of a relevant subset of the treated products. Part of the effects is related to the poster treatment per se, and part is attributable to consumers' price inelasticity in the poster-plus-price-change treatments.

Furthermore, under the assumption that consumption of some of the products on which our experiment is conducted does not significantly contribute to consumers' health, a significant effect of our treatment may be interpreted as contributing to the more general literature on otherregarding preferences. Although food security is what consumers consider first among several label components (Loureiro and Umberger, 2007), the ample literature in this field developed and empirically tested several concepts such as reciprocity (Rabin, 1993), inequity aversion (Fehr and Schmidt, 1999; Bolton and Ockenfels, 2000), pure and impure altruism (Andreoni, 1989, 1990), and social welfare preferences (Charness and Rabin, 2002). Most of the empirical evidence documented in this literature hinges on laboratory experiments: the use of field experiments to test for the existence of other-regarding preferences is therefore a clear added value, especially for the external validity of the empirical results.

The findings of this paper have straightforward policy implications (as we discuss in detail in Section 7). If public information in shops on environmentally sustainable products is found to have a significant effect on customers, this approach to the provision of proper information and elicitation of consumers' environmental preferences may significantly help policymakers achieve social and environmental goals at a lower cost than taxes or regulation.

\footnotetext{
${ }^{3}$ Several other contributions have found that the consumers' willingness to pay for sustainable products is related to the distance of transportation, identifying a preference for local sustainable products (Grebitus et al., 2013; Onozaka and McFadden, 2011; Caputo et al., 2013a,b; Van Loo et al., 2014). Van Loo et al. (2017) mention increasing consumers' motivation for health and sustainability and strong matching and compatibility between the two concepts in their perception. Aschemann-Witzel (2015) argues that a better understanding of the links between the two can contribute to the achievement of both goals. Other studies focus on what type of information is more effective in stimulating more consumers' willingness to pay. Caputo et al. (2013a,b) find that consumers value $\mathrm{CO}_{2}$ labels as much as, if not more than, miles labels on sustainable products.
} 


\section{Experiment design}

Our experiment is conducted in 12 Coop Italia (Coop) grocery stores. Coop is a system of Italian consumers' cooperatives operating the biggest Italian grocery store chain. ${ }_{-}^{4}$ The stores were selected among those with the highest sales in the region of Tuscany where Unicoop Firenze, one of the biggest Coop cooperatives, mainly operates. Our analysis focuses on the Vivi Verde (VV) brand, a line of Coop products with a low ecological footprint. VV food products are organic products, and VV non-food products are "EU Ecolabel" generally, environmentally sustainable labeled products.

During the treatment phases, we place a label on the shelves where VV products are located. The label is titled "Why buy Vivi Verde" and says, "This product comes from organic farming and was designed by considering its environmental impact. By purchasing this product lat a fair price] you are supporting environmentally responsible producer policies. A cleaner world is better also for you" (Figure 1). The first part of the message is the official product information, which is also displayed on the Coop website. The second part highlights the positive externality of the purchase. The label is designed by the Coop marketing staff and is written in Italian. The title and the message display the same font size as the price and the product name, respectively.

We implement three types of treatments: the "label" (Label), the "label plus $5 \%$ price increase" (Label5), and the "label plus 10\% price increase" (Label10). In the Label treatment, we introduce the shelf poster without changing product prices. In the Label5 and the Label10 treatments, we introduce the shelf poster and raise the prices of the VV products by $5 \%$ and $10 \%$, respectively, to test for a moderate and a strong price change effect. We adopt a two-phase, two-group crossover design (Jones and Kenward, 2003) with stores randomly assigned to a treatmentcontrol sequence or vice versa (Table 1). Phase 1 was implemented from May 30 to June 26, 2016, and Phase 2 was implemented from June 27 to July $24,2016 .{ }^{6}$ The crossover design is more efficient than a simple parallel group design because if we assume no carry-over, we can exploit

\footnotetext{
${ }^{4}$ In 2016, the Coop was the leader among grocery retailers in Italy, with a $10 \%$ share of sales value (Euromonitor International, 2016).

${ }^{5}$ The EU Ecolabel is an EU-recognized label that identifies products and services with a reduced environmental impact. This certification is developed and reviewed every 3-5 years by experts, the industry, consumers' organizations, and environmental nongovernmental organizations. The Ecolabel certification fulfills the ISO14020 Type 1 requirements, and in its most recent update, the scope has expanded to new product types to consider the principles of the circular economy. For more information see http://ec.europa.eu/environment/ecolabel/.

${ }^{6}$ One store in group 2 started the treatment phase three days after the other stores, and thus it ended three days later.
} 
within-store variation for each store. The no carry-over assumption may be violated if consumers in the treatment-control sequence continue to choose products in phase 2 (control) because of information learned during phase 1 (treatment). We rely on the following: The violation of the no carry assumption provides a downward bias for the poster effect because consumers who already know the information simply continue to be sensitive to the treatment even during the control phase. To check the no carry-over assumption, we perform a robustness check that assesses the stores in Group 2 (treatment-control sequence) during the last two weeks of each phase.

For our experiment, we select 22 out of $270 \mathrm{VV}$ products (Table $\underline{2}$ ). Because green products may also be purchased for health reasons, our sample comprises i) food products, ii) non-food products that may be in contact with the human body (e.g., dish detergents and lip protectors), iii) non-food products that produce emissions that can be inhaled (e.g., surface cleaners), and iv) non-food products that are not in any of the aforementioned categories and do not come into direct contact with the human body (e.g., disposable table covers and bin liners).

We periodically check that the experiments were performed correctly during treatment and control periods and took photographs to confirm that the treatment was properly implemented. At the end of the experiment, we collect scanner panel data of the quantity sold and revenues for each product. Scanner data is preferable because it embeds external reference prices (Mayhew

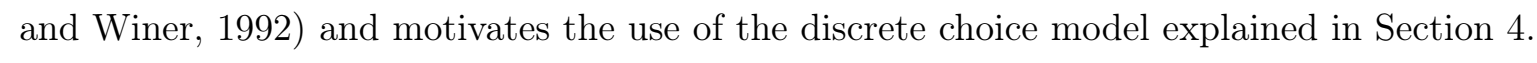

\section{Methodology}

\subsection{Discrete choice model}

The econometric specification presented in Section $\underline{6}$ is based on the theoretical benchmark in $\underline{\text { Nevo }} \underline{(2010)}$. The indirect utility of consumer $i$ from consuming good $j$ in market $m$ can be written as

$$
U_{i j m}=U\left(x_{j m}, \xi_{j m}, I_{i}-p_{j m}, \tau_{i} ; \theta\right)
$$

where $x_{j m}$ is a vector of observed good characteristics; $\xi_{j m}$ is a vector of good characteristics that researchers do not observe and that can include systematic demand shocks, unobserved promotional activity, or the positive value perception of the treated products for consumers with other-regarding preferences-the introduction of $\xi_{j m}$ helps explain the data and implies that if 
firms observe $\xi_{j m}$ before making production plans, prices and other choice variables could be endogenous; $I_{i}-p_{j m}$ represents the income-price difference; $\tau_{i}$ are individual characteristics; and $\theta$ is a vector of parameters to be estimated.

Nevo (2010) also proposes a simplified version of indirect utility which he writes as

$$
u_{i j m}=\alpha\left(I_{i}-p_{j m}\right)+\beta x_{j m}+\xi_{j m}+\varepsilon_{i j m}
$$

where $\varepsilon_{i j m}$ is a stochastic term, $\alpha$ is the marginal utility from net income, and $\beta$ is a $K \times 1$ vector of specific taste coefficients. The model also assumes $\varepsilon_{i j m}$ are iid and follow a Gumbel distribution.

The individual indirect utility from the outside option, that is, from not purchasing any of the goods, is given by

$$
u_{i 0 m}=\alpha_{i} I_{i}+\varepsilon_{i 0 m}
$$

Because our interest is in relative utilities, we can express individual indirect utility from a generic good $j$ belonging to market $m$ by removing the individual income term $I_{i}$. Thus, we obtain

$$
u_{i j m}=\delta_{j m}+\varepsilon_{i j m}
$$

where $\delta_{j m}=x_{j m} \beta-\alpha p_{j m}+\xi_{j m}$ is the mean utility across consumers and the random term $\varepsilon_{i j m}$ captures the variation around the mean utility $\delta_{j m}$.

The probability that a consumer of type $\left(D_{i}, v_{i}\right)$, where $D_{i}$ and $v_{i}$ represent respectively observed and unobserved individual characteristics, chooses good $j$ is

$$
s_{i j m}=\int \mathbb{1}\left[u_{i j m} \geq u_{i k m} \forall l \mid x_{m}, \delta_{m}, p_{m}, D_{i}, v_{i} ; \theta\right] d F_{\varepsilon}(\varepsilon)
$$

where $\mathbb{1}[\cdot]$ is the indicator function.

Thus, market shares $s_{j m}$ are given by the sum of individual market shares $s_{i j m}$ over the distributions of individual characteristics, and based on our model, assumptions can be written as

$$
s_{j m}=\frac{\exp \left\{x_{j m} \beta-\alpha p_{j m}+\xi_{j m}\right\}}{1+\sum_{k=1}^{J} \exp \left\{x_{j m} \beta-\alpha p_{j m}+\xi_{j m}\right\}} .
$$


We refer to Berry (1994) and Hainmueller et al. $(2015)$ and write the mean utility as a function of observed market shares, that is, $\delta_{j m}=\log s_{j m}-\log s_{0 m}$, and we use it in our main econometric estimation $(2)$ in section 6 .

\subsection{Hypotheses testing}

With our experiment, we test four hypotheses for each treatment $T_{i}$ : Label $\left(T_{1}\right)$, Label5 $\left(T_{2}\right)$, Label10 $\left(T_{3}\right)$, and the aggregated treatments $\left(T_{4}\right)$, vis-á-vis control condition $C$. In particular, we assess the expected value $\mathbb{E}[\cdot]$ of total sales for food products $\left(S_{f}\right)$ and non-food products $\left(S_{n f}\right)$, and market shares in each market $\left(\delta_{j m}\right)$.

The first hypothesis is the insignificance of the $i$-th treatment for any of the VV products in the treated product class $m$ :

$H_{01}^{T_{i}}: \mathbb{E}\left[\delta_{j m}^{C}\right]=\mathbb{E}\left[\delta_{j m}^{T_{i}}\right]$ for each $i, m$

The null $H_{01}^{T_{i}}$ states that the $i$-th treatment has no effect on consumers' choices, that is, the treatment does not change the $m$ market shares in the experiment. This phenomenon would occur in the presence of purely self-regarding consumer preferences, or no concern for health related problems arising from the purchase of less environmentally sustainable products, or other unobserved motivations such as conspicuous consumption aversion or time preferences. Rejection of the null for some of the VV products would imply that information on corporate environmental responsibility is a strategy that marketing experts or policymakers may successfully implement to affect product sales and address environmental concerns.

The second null hypothesis is

$H_{02}^{T_{i}}: \mathbb{E}\left[S_{f}^{C}\right]=\mathbb{E}\left[S_{f}^{T_{i}}\right]$ for each $i$.

It states that the treatment does not affect aggregate sales of VV food products, that is, aggregate sales of VV food products do not significantly change when the treatment is introduced. The rejection of the null again implies that our nudge works and can be successfully implemented for marketing or welfare purposes. Even in this case, rejection of the null would support the existence of the other-regarding preferences component. However, when, $i=2,3$, and 4 , a failure to reject the null might also be a result of the price increase in treatments Label5 and Label10 and therefore does not imply that the treatment is not effective. 
The third null hypothesis is

$H_{03}^{T i}: \mathbb{E}\left[S_{n f}^{C}\right]=\mathbb{E}\left[S_{n f}^{T_{i}}\right]$ for each $i$.

It states that the treatment does not affect aggregate sales of VV non-food products. Notably, rejection of the null in the direction of higher market shares of VV non-food products under the treatment (the shelf poster on environmental sustainability) would be supportive of the presence of other-regarding preferences. Notably, non-food product purchases are less likely to be affected by other motivations such as health concerns. At the end of Section $\underline{6}$ and in Section $\underline{7}$, we further investigate the role of health concerns. Similar to hypothesis $H_{02}^{T_{i}}$, for $i=2,3$, and 4 , a failure to reject the null might also be considered a compensation for the price increase and does not imply that the treatment is not effective. ${ }^{7}$

To disentangle the role of other-regarding preferences from the influence of health concerns, we also formulate hypothesis four:

$H_{04}^{T i}: \mathbb{E}\left[\delta_{z}^{C}\right]=\mathbb{E}\left[\delta_{z}^{T_{i}}\right]$ for each $i$

where $z$ is the set of non-food products that have neither a relation with nor come into direct contact with the human body. The fourth null is a sharper test of the existence of other-regarding preferences because the product object of our test is the least likely to have consequences on consumers' health. More specifically, in this respect, we consider a taxonomy of four types of products according to consumers' perception of their potential impact on health: i) food products, ii) non-food products that enter directly or indirectly into contact with the human body (i.e., lip protectors, dish detergents, shower products, and napkins), iii) non-food products that produce emissions that can be inhaled (i.e., surface cleaners), iv) non-food products that have neither a relation with nor a direct exposition to the human body. (i.e., table covers or bin liners). The null $H_{04}^{T i}$ relates to the effect of the treatment on products in category iv), and its rejection would suggest the presence of other-regarding preferences.

\section{Descriptive statistics}

Table $\underline{2}$ shows the list of products that are labeled, divided by product class with their relative prices. Product classes are defined by Coop and reflect the physical arrangement of the products

\footnotetext{
${ }^{7}$ In an out-of-sample online survey on Coop consumers, we find evidence that our assumption is correct because the respondents say that food products affect their health more than other consumers' health, and the reverse occurs for non-food products including table covers. For a detailed discussion of these findings, see Appendix C.
} 
on the shelves. This allows us to consider all the products within a selected class as substitutes.

In Table $\underline{3}$, the randomization checks for each treatment type are presented. ${ }_{-}^{8}$ We observe that within each treatment type, shops assigned to different sequences (i.e., control-treatment or treatment-control) do not differ in total sales and other neighborhood characteristics.

Tables $\underline{4}$ and $\underline{5}$ and present sales across different stores and treatment types, respectively. Aggregate sales increase by approximately $1 \%$ under the treatment phase both in total and in the selected classes, even if this increase is not homogeneous across the stores (Table 4) and treatment types (Table 5). In particular, total VV sales increase by $1.7 \%$ overall and by $6 \%$ under Label 5 treatment. However, under Label10 treatment, sales decrease by $2.3 \%$ (Table $\underline{5}$ ). Table $\underline{6}$ shows total sales and VV sales in each of the selected classes. These weak aggregate findings conceal strong heterogeneity in the treatment effects across the VV products. The following econometric analysis provides insights into this seemingly insignificant effect of the treatment when viewed at the aggregate level with descriptive findings.

\section{Econometric analysis}

To measure the impact of the gross treatment effect, we first perform a reduced-form econometric analysis and then estimate a complete model. Using a simple specification that partly follows Hainmueller et al. (2015), we regress the natural logarithm of the weekly VV sales on the treatment indicators controlling for week/store fixed effects and prices. We split the 18 selected product classes into two groups: food products and non-food products. In particular, we regress the following reduced-form specification:

$$
\log \left(s_{i, w}\right)=\alpha+\beta_{0} \text { Treatment }_{w}+\sum_{h} \alpha_{1, h} \text { Week }_{h}+\sum_{k} \alpha_{2, k} \text { Store }_{h}+\alpha_{3} \text { Price }_{i, w}+\epsilon_{i, w}
$$

where $\log \left(s_{i, w}\right)$ is the $\log$ of the sales of the VV product $i$ in week $w$, Treatment $w_{w}$ is a $(0 / 1)$ dummy during the treatment phase (total and separated for each treatment), and $W_{e e k_{h}}$ and Store $_{k}$ capture the week and store fixed effects. We also control for the price of product $i$ in week $w$, Price ${ }_{i, w}$. We consider as the outside option the aggregate of all brands with market shares lower than $4 \%$, with some exceptions for markets with a limited number of brands where we

\footnotetext{
${ }^{8}$ Given the limited number of stores used in the experiment, we cannot perform a statistical test of the balancing properties between the treatment and control groups.
} 
considered the brands with the smallest market shares. All the standard errors are clustered at the store level to consider potential within-store correlation over time.

Table $\underline{7}$ shows that the overall effect of the treatment is positive and statistically significant for the food products. In terms of economic significance, the treatment generates a $2 \%$ growth in sales. When we decompose the effect into the three treatments (Label, Label5, and Label10) we find an aggregate food effect concentrated on the $10 \%$ price increase treatment, with a $4.3 \%$ growth in log sales. Therefore, we reject the null hypotheses $H_{02}^{T_{3}}$ and $H_{02}^{T_{4}}$. The non-food products show different results, with the treatment being negative but not strongly significant overall and concentrated on the Label treatment only. These results seem to be in line with the idea that higher environmental concerns induce the purchase of organic food, albeit expensive, and they reduce (or do not increase) the consumption of many non-food products to reduce waste, especially disposable products. Therefore, we reject null hypotheses $H_{02}^{T_{1}}$ and $H_{02}^{T_{4}}$.

These summary aggregate econometric findings must be decomposed to understand how the treated product market shares perform within each product class. This method is particularly relevant for non-food products where total sales may be reduced overall but the VV product may increase market shares as a result of a treatment label that increases environmental concerns.

To test whether our treatments are significant, we refer to Berry $\underline{\text { 1994) }}$ and Hainmueller et al. $\underline{(2015)}$ and estimate for each market (i.e., product class) the following fully specified model

$$
\begin{aligned}
\delta_{i j t}= & \beta_{0} \text { TreatVV }+\sum_{b} \beta_{1, b} \text { TreatBrand }_{b} \\
& +\sum_{h} \alpha_{1, h} \text { Week }_{h}+\sum_{k} \alpha_{2, k} \text { BrandStore }_{k}+\alpha_{3} \text { Price }_{i j t}+\epsilon_{i j t}
\end{aligned}
$$

where $\delta_{i j t}=\log \left(s_{i j t}\right)-\log \left(s_{00 t}\right)$ is the observed market share for good $i$ belonging to brand $j$ at week $t$; $\operatorname{Treat}_{\mathrm{V}} \mathrm{V}_{b}$ is a $(0 / 1)$ dummy for the $\mathrm{VV}$ brand during the treatment phase; TreatBrand $\mathrm{d}_{b}$ is a $(0 / 1)$ dummy for the brands within the same product class of the VV treated products during the treatment phase; Week $_{h}$ and BrandStore ${ }_{k}$ are (0/1) dummy variables capturing the week and the brand/store fixed effects, respectively; and Price $_{i j t}$ represents the unit price level of good $i$ belonging to brand $j$ at week $t$. We cluster standard errors at the store level to consider any possible time-varying non-observable store-level effect.

Our method differs from the standard discrete choice model (Nevo, 2010): We use brand rather than product market share because our interest is investigating the effect of the treatment on 
the VV brand. We also control for the price level, a variable that should matter especially under the Label5 and Label10 treatments.

The econometric findings presented in Table $\underline{8}$ show that the treatment is significant for nine of 18 products (though weakly so in one case). The effect is unevenly distributed among the three treatments (Label, Label5, and Label10); therefore, we reject the null hypotheses $\left(H_{01}^{T_{i}}\right.$ for each i) in Section 4.2. In terms of economic significance, the strongest effect is the $53 \%$ increase in fruit juices, and many other significant effects are above the $20 \%$ increase in magnitude.

Another characteristic of our findings is that the significance of the treatment seems to be stronger for food than for non-food product classes, supporting aggregate findings on total sales presented in Table 7. More specifically, of the eight food product classes, the treatment is significant for five: teas, whole wheat pasta, bread and substitutes, tomato preserves, fruit juices, and white kidney beans. The only classes where the treatment is not significant are tomato preserves and long- and short-cut wheat pasta. Among the 10 non-food classes, the treatment effect is significant for four classes: big surface cleaners, disposable table covers, tablecloths and napkins, and lip protectors. If we assume that disposable table covers (and tablecloths and napkins) have no relation to the human body, we reject hypothesis $H_{04}^{T_{1}}$ (and $H_{04}^{T_{2}}, H_{04}^{T_{3}}$, and $H_{04}^{T_{4}}$ ).

We also compute the own price elasticity with the estimated demand in each product class of demand for VV products. Table 9 shows the point estimate and the $90 \%$ confidence interval of the price elasticity for each market in treatments Label5 and Label10. We observe that the elasticity is negative and significant for four VV products: dish detergents, bin liners, disposable table covers, and handkerchiefs. In seven classes, however, the elasticity of the treated VV products is positive and significant, suggesting that our label makes the demand for many VV products inelastic.

The lack of significance in the Label5 and Label10 treatments for some markets does not necessarily imply a non-result. A price increase should produce a significant and negative effect in the presence of normal goods with a "negative" income effect (inverse relationship between demand change and price change) accompanying the always "negative" substitution effect (inverse relationship between demand change and price change). Notably, positive elasticities can occur as a combined result of the label effect and price change. If the label effect dominates, we observe an increase in consumption in the presence of a price increase. There is no difference between 
the control and the treatment phase except for the label (in the Label treatment) and the price (in the Label5 and Label10 treatments). Hence, the product quality remains constant during all experiment periods. Notably, the positive reaction of consumers to the label may imply that in addition to the signal on the environmental characteristics, other product properties are concerned, such as the health benefit and overall quality. This may explains the insignificant effect when the price is not changed and the positive and significant effect when the price increases.

Finally, to check the no carry-over assumption, we perform reduced-form analysis with stores assigned to the treatment-control sequence only and during the last two weeks. Table 10 confirms the validity of this hypothesis.

\section{Discussion}

In this section, we discuss how our econometric findings contextualize within the theory. As explained in the introduction, one of the original characteristics of our natural field experiment comprises the simultaneous application of the treatment on a large set of products and not on one product only as in the literature, for example, Hainmueller et al. $\underline{(2015)}$. In addition, there are strong differences in the "ethical" characteristics of Fair Trade and VV products that are reflected in the differences in the treatment labels of the two experiments. Fair Trade criteria focus on commodity producers' sustainability (fair price, counter-cyclical price stabilization mechanisms, capacity building to ease access to foreign markets). Hainmueller et al. $\underline{\text { (2015) }}$ consistently place a label saying that the product is Fair Trade Certified and added the sentence "A fair price to support Fair Trade." By contrast, our label exclusively focuses on environmental responsibility characteristics (no explicit mention of labor), consistent with the actual characteristics of the VV products described in section $\underline{3}$.

Our research question addresses which products are more affected after performing a nudging treatment on many products. An unrealistic expectation would be that the treatment increases the expenditure on all the treated products, because this could produce too strong an impact on the aggregate increase in expenditure. The expected selection of effects on the treated products should produce redistributive effects implying a hierarchy of preferences among them. Hence, the experiment allows us to understand the products for which there is more scope for sales improvement through green nudging, and which of their characteristics are more likely to determine such improvement (our null hypotheses $2-4$ relate to this last point). 
At a descriptive level, we observe that total, selected product classes, and VV sales increase during the treatment phase. This increase makes the experiment profitable for the grocery store chain because Coop is the main stakeholder and owns VV products. Although a priori the profitability of the experiment was not obvious, this result may encourage Coop and other grocery store chains to replicate similar cost-free pro-environment treatments.

The empirical analysis documents an overall increase in treated products' market shares under the treatment conditions. The pattern of the economic significance of the treatment effects is not negligible, especially if we consider that at least three factors may contribute to reducing the impact of our treatment. First, our experiment was conducted at the end of a long recession period in Italy (OECD, 2015), started by the global financial crisis, that led to a $12 \%$ reduction in Italian household income. Therefore, we reasonably assume that the willingness to pay for environmentally sustainable food products may have been weakened by the prolonged crisis in this historical period. Second, Coop supermarkets are attended by consumers who are more sensitive to sustainability than average because most of them are also shareholders of the Coop chain, and the Coop movement has a long tradition of sensitivity to social and environmental issues (see also the findings on our third question in the supplementary survey in Appendix $\mathrm{C}$ ). We therefore expect the shares of the VV products to already be at high levels, and room for further improvement is thus limited. Third, the photo of our experiment setting (Figures 2 ) shows that the shelf poster has a message printed in a standard low size font that may not be easily read by consumers with poor eyesight. In this sense, our goal was to test whether even a weak green nudging signal could produce significant effects on consumption shares of the treated products.

The majority of our significant results show that the size of the treatment effect is between $10 \%$ and $50 \%$ of the market share. This percentage is slightly higher than the premium found by Hainmueller et al. (2015) (approximately 10\%). However, the novelty of our labels simultaneously applied to multiple product categories makes any comparison difficult to explain.

Although we interpret the significant effect of the treatment on some product classes as the effectiveness of our nudge, we also propose a possible explanation for the non-significant effect on the remaining product classes. In particular, we find no effect on non-whole wheat pasta, tomato preserves, dish detergents, small surface cleaners, bin liners, bathroom products, toilet paper, and handkerchiefs. The absence of the effect on pasta may be explained by the presence of the 
same nudge on both whole wheat and non-whole wheat pasta, with the latter being perceived as vice (less healthy) food and the former as healthy, consistently with the aforementioned literature on willingness to pay for organic vice food (Van Doorn and Verhoef, 2011). Although such distinction is beyond our research goal, the high- and low-quality food distinction may also explain why our nudge works with the price increase for some products while without a price change for products. Regarding non-food categories, our nudge concerns environmentally responsible behavior and, as such, may act as a stimulus not to buy these products. Notably, once individuals are nudged to buy responsibly, they may realize that many products such as dish detergents or handkerchiefs can be reduced or eliminated from their shopping basket. However, we are aware that his speculative interpretation is not statistically tested.

A final important finding of our experiment is related to the consequences of our results on the hypothesis of the existence of other-regarding preferences among our sample consumers. The self-regarding health effect is presumed to be stronger on food products that enter consumers' body, weaker but still present on products that come into contact with consumers' body (e.g., lip protectors), and even weaker on products that do not enter into contact with consumers' body but that emit substances that can be inhaled (e.g., surface cleaners and detergents). ${ }_{-}^{9}$ The only products that have none of these three characteristics are disposable table covers and bin liners. Our findings show that our treatment is significant for table covers and therefore provides evidence in favor of rejection of $\left(H_{04}\right)$, that is, the null of the absence of other-regarding preferences.

Last, one maintained assumption of our research is that consumers believe that the treatment significantly affects other consumers' choices. To verify the reliability of this assumption, we conduct an out-of-sample online survey on Coop consumers. The online survey reveals that more than $80 \%$ of respondents believe that the treatment affects significantly and in the expected direction the other consumers who are also subject to the treatment (approximately 30\% believe in a strong or very strong impact, approximately $30 \%$ in a fair impact, approximately $20 \%$ in at least a low impact, and we observed some variation across different product classes). The results are fully discussed in Appendix $\underline{\mathrm{C}}$.

\footnotetext{
${ }^{9}$ We test this hypothesis in an out-of-sample online survey discussed in Appendix C.
} 


\section{Policy implications}

Our experimental findings lead us to four relevant policy implications that might significantly boost environmental sustainability and require no financial expenditure from the government.

First, local, regional, national, or supranational (i.e., EU level) administrations could impose regulations that require brands and retail outlets to expose labels similar to those used in our experiment when selling products with ecological certification. This choice would fully comply with a libertarian paternalistic approach that does not alter the choice set of consumers and simultaneously focuses them on the positive externalities of their environmentally sustainable purchase. Standard textbook economic models often postulate that consumers, for example, "Econs", are fully aware of product characteristics (i.e., monetary and non-monetary) and the environmental impact of their purchases. Notably, the majority of consumers only know and observe product prices. Putting up labels similar to those used in our experiment would make consumers aware of non-price characteristics, reduce their incomplete information, and make them reflect on the broad social impact of their purchases.

Second, supermarkets have an interest in gathering and displaying the corporate social responsibility (CSR) information of their products' suppliers, especially for the most virtuous ones. This practice improves the grocery store chains' CSR reputation and incentivizes suppliers to improve their CSR reputation. At the end of our experiment, Coop implemented a project based on this idea aimed at making producers' CSR ratings more visible.

Third, companies selling environmentally sustainable products could further emphasize their green characteristics and their effects on the economic environment as a marketing policy, to capture the consumers' willingness to pay for these characteristics.

Fourth, local, regional, national, or supranational (i.e., EU level) administrations could devise budget-balanced tax/subsidy schemes to stimulate environmentally responsible choices. We show in the experiment that eliciting the willingness to pay for environmentally sustainable food products makes some consumers price inelastic, leading them to choose the VV product even when the price increased. Therefore, an economic incentive might increase the share of sales of environmentally sustainable products. For example, given two equivalent products, one environmentally responsible and one not, a typical scheme is a lump-sum tax paid by consumers 
buying the non-environmentally responsible product, with the total tax proceeds shared across buyers of the environmentally responsible product. This policy is at zero cost for decision-makers and has the advantage (disadvantage) of providing larger (fewer) benefits for responsible buyers whenever their share is small (large). Different from other lump-sum mechanisms, for example, the feed-in-tariff (Couture and Gagnon, 2010; European Commission, 2008; REN21, 2009), the negative relationship between the incentive and the share of responsible buyers is not necessarily a problem. When the latter is large, we may assume that a social norm of buying environmentally responsible products is already enforced and therefore economic incentives become less important.

We acknowledge that our sample of loyal Coop consumers may not allow our results to be validated in other contexts. In our sample, customers already sensitive to sustainability may be over-represented. On the one hand, this limitation could have dampened the effects of the treatment if the consumers were already behaving responsibly; on the other hand, the treatment could have led to a more pronounced effect if the consumers had a stronger response to the nudge. Therefore, the policy we suggest should take any external validity problem into account and analyze the social context and consumers responsiveness before implementation.

\section{Conclusions}

We perform a green nudging natural experiment with crossover design by using as a treatment a poster on supermarket shelves explaining the importance of environmental responsibility for 18 green (VV) products. Our findings document a statistically and economically significant effect on treated products' market shares for several relevant product classes. Part of the effect is determined by the price inelasticity of consumers in the poster-plus-price-increase (Label5, Label10) treatments, as shown by our estimated elasticities. Evidence of the significance of the treatment effect was also observed on non-food products that presumably have limited effects on personal health; the evidence of the significance on table covers where health effects are irrelevant was stronger and suggests that the significant reaction to the treatment effect is partially because of the presence of non-purely self-regarding preferences.

Our experiment shows that emphasizing environmentally responsible features of products in strategic places is a low cost, high impact policy that may significantly shift consumers toward 
green purchases. The cost-effectiveness of such policies should be compared with those based on more traditional incentive schemes. In a sense, the problem with environmental sustainability is that corporate profit functions do not internalize the negative environmental externalities of firm choices along the supply chain (notably, in terms of emissions and waste management). The provision of information to the final consumers on their level of environmental responsibility at selling places may in this respect be crucial to internalize the negative social costs of such externalities and could contribute to bridging the gap between private and social optimum.

Our findings have several implications for further research and policy. In further research, researchers could ask these two questions: What would the aggregate effects be of the provision of such information on a large scale? and Would these effects contribute to modifying the costs and rewards of environmentally sustainable choices at the corporate level? Further research could also attempt to estimate the effect of social and environmental information providers such as online food outlets or user-rated sellers in different domains (e.g., the TripAdvisor system for restaurants) as a stimulus for the production and the diffusion of information in this specific domain to the general public. Notably, if these aggregate effects exist, at least four policies (compulsory CSR information, voluntary CSR information programs by companies and distributors, emphasis on green characteristics on marketing, and design of budget-balanced tax/subsidy schemes by governments) can have a further role in shifting consumption toward increased sustainable products.

\section{References}

Allcott, H. (2011). Social norms and energy conservation. Journal of Public Economics 95(9), $1082-1095$.

Andreoni, J. (1989). Giving with impure altruism: applications to charity and ricardian equivalence. Journal of Political Economy 97(6), 1447-58.

Andreoni, J. (1990). Impure altruism and donations to public goods: a theory of warm-glow giving?. Economic Journal 100(401), 464-77.

Aschemann-Witzel, J. (2015). Consumer perception and trends about health and sustainability: trade-offs and synergies of two pivotal issues. Current Opinion in Food Science 3, 6-10. 
Atkinson, A. B., and J. E. Stiglitz (1980). Lectures on public economics. McGraw-Hill: Maidenhead, UK.

Barton, A. and Grüne-Yanoff, T. (2015). From libertarian paternalism to nudging-and beyond. Review of Philosophy and psychology 6(3), 341-359.

Becchetti, L. and Salustri, F. (2019), The Vote with the Wallet game: Responsible consumerism as a multiplayer prisoner's dilemma, Sustainability 11(4), 1109.

Becchetti, L., Salustri, F., and Scaramozzino, P. (2019). Making information on CSR scores salient: a randomized field experiment. Oxford Bulletin of Economics and Statistics 81(6), $1193-1213$.

Berry, S.T. (1994). Estimating discrete-choice models of product differentiation. The RAND Journal of Economics 242-262.

Bolton, G., and Ockenfels, A. (2000). ERC: A theory of equity, reciprocity, and competition. American Economic Review 90(1), 166-193.

Brekke K.A, S. Kverndokk, K. Nyborg (2003). An economic model of moral motivation. Journal of Public Economics 87, 1967-83.

Caputo, V., Nayga Jr, R.M., and Scarpa, R. (2013a). Food miles or carbon emissions? Exploring labelling preference for food transport footprint with a stated choice study. Australian Journal of Agricultural and Resource Economics 57(4), 465-482.

Caputo, V., Vassilopoulos, A., Nayga Jr, R.M., and Canavari, M. (2013b). Welfare effects of food miles labels. Journal of Consumer Affairs 47(2), 311-327.

Carlsson, F. and O. Johansson-Stenman (2012). Behavioral economics and environmental policy. Annual Review of Resource Economics 4(1), 75-99.

Charness, G. and Rabin, M. (2002). Understanding social preferences with simple tests. The Quarterly Journal of Economics 117(3), 817-869.

Couture, T. and Y. Gagnon (2010). An analysis of feed-in tariff remuneration models: Implications for renewable energy investment. Energy Policy 38, 955-965.

Euromonitor International, Grocery Retailers in Italy 2016, Country Report, 47 pages. 
European Commission (2008). The support of electricity from renewable energy sources. Commission Staff Working Document, SEC(2008) 57.

Fehr, E. and Schmidt, K.M. (1999). A theory of fairness, competition and cooperation. The Quarterly Journal of Economics 114, 817-868.

Fisher, A. C. (1981). Resource and environmental economics. Cambridge University Press: Cambridge, UK.

Goldstein, N., Cialdini, R., and Griskevicius, V. (2008). A room with a viewpoint: Using social norms to motivate environmental conservation in hotels. Journal of Consumer Research 35(3), $472-482$.

Goldstein, N.J. and Cialdini, R.B. (2009), Normative influences on consumption and conservation behaviors' In M. Wänke (Ed.). Social psychology of consumer behavior. 273-296, New York: Psychology Press.

Grebitus, C., Lusk, J.L., and Nayga Jr, R.M. (2013). Effect of distance of transportation on willingness to pay for food. Ecological economics 88, 67-75.

Griskevicius,V., Cialdini, R.B., and Goldstein, N.J. (2008). Social norms: An underestimated and underemployed lever for managing climate change. International Journal for Sustainability Communication 3, 5-13.

Hainmueller, J., M.J. Hiscox, and S. Sequeira (2015). Consumer demand for fair trade: Evidence from a multistore field experiment. The Review of Economics and Statistics 97(2), 242-256.

Hansen, P.G. (2016). The definition of nudge and libertarian paternalism: does the hand fit the glove? European Journal of Risk Regulation 7(1), 155-174.

Hansen, P.G. (2019). The concept of nudge and nudging in behavioural public policy, in H. Straßheim and S. Beck (eds.). Handbook of behavioural change and public policy. 63-77, Edward Elgar: Cheltenham, UK, and Northampton, USA.

Harrison, G.W. and J.A. List (2004). Field experiments. Journal of Economic literature 42(4), 1009-1055.

Hausman, D.M. and B. Welch (2010). Debate: to nudge or not to nudge. The Journal of Political Philosophy 18(1), 123-136. 
Hiscox, M.J., Broukhim M. and Litwin C. (2011), Consumer demand for fair trade: New evidence from a field experiment using eBay auctions of fresh roasted coffee. Available at: http://dx.doi.org/10.2139/ssrn.1811783.

Hudson, D., Gallardo, R.L. and Hanson, T.R. (2012) "A comparison of choice experiments and actual grocery store behavior: An empirical application to seafood products. Journal of Agricultural and Applied Economics 44(1), 49-62.

Jones, B. and Kenward, M.G. (2003), Design and analysis of cross-over trials, Second Edition (Monographs on Statistics and Applied Probability). New York: Chapman \& Hall

Just, D.R. (2017). The behavioral welfare paradox: practical, ethical and welfare implications of nudging. Agricultural and Resource Economics Review 46(1), 1-20.

Loureiro, M.L. (2003). Rethinking new wines: implications of local and environmentally friendly labels. Food Policy 28 (5-6), 547-560.

Loureiro M.L. and J. Lotade (2005). Do fair trade and eco-labels in coffee wake up the consumer conscience? Ecological economics 53(1), 129-138.

Loureiro, M.L. and W.J. Umberger (2007). A choice experiment model for beef: What US consumer responses tell us about relative preferences for food safety, country-of-origin labeling and traceability. Food policy 32(4), 496-514.

Lusk, J.L. (2014). Are you smart enough to know what to eat? A critique of behavioural economics as justification for regulation. European Review of Agricultural Economics 41(3), $355-373$.

Mansky, C.F. (1977). The structure of random utility models. Theory and Decision 8(3), 229-254.

Mayhew, G. E. and Winer, R. S. (1992). An empirical analysis of internal and external reference prices using scanner data. Journal of Consumer Research 19(1), 62-70.

McFadden, D. (1981), Econometric Models of Probabilistic Choice in C.F. Manski and D. McFadden (eds.). Structural analysis od discrete data with econometric applications. 198-272, MIT Press: Cambridge, MA.

McFadden, D. (1984), Econometric analysis of qualitative response models ch. 24, 1395-1457 in Grilichest, Z. and Intriligator, M.D. eds. Handbook of Econometrics 2, Elsevier. 
Mongin, P., and M. Cozic (2014). Rethinking nudge. HEC Paris Research Paper No. ECO/SCD2014-1067.

Mongin, P., and M. Cozic (2018). Rethinking nudge: not one but three concepts. Behavioural public policy 2(01), 107-124.

Murray, K.B., Di Muro, F., Finn, A. and Popkowski Leszczyc, P. (2010). The effect of weather on consumer spending. Journal of Retailing and Consumer Services 17, 512-520.

Nevo, A. (2010). Empirical models of consumer behavior. Annual Review of Economics 3, 51-75.

OECD - Better Life Initiative Country Note (2015), How's life in Italy. Available at https: //www.oecd.org/statistics/Better\%20Life\%20Initiative\%20country\%20note\%20Italy.pdf.

Oliver, A. (2013). From nudging to budging: using behavioural economics to inform public sector policy. Journal of Social Policy 42(4), 685-700.

Onozaka, Y. and McFadden, D.T. (2011). Does local labeling complement or compete with other sustainable labels? A conjoint analysis of direct and joint values for fresh produce claim. American Journal of Agricultural Economics 93(3), 693-706.

Parker, P.M. and Tavassoli, N.T. (2000). Homeostasis and consumer behavior across cultures. International Journal of Research in Marketing 17, 33-53.

Parsons, A.G. (2001). The association between daily weather and daily shopping patterns. Australasian Marketing Journal 9(2), 78-84.

Rabin, M. (1993). Incorporating fairness into Game theory and Economics. American Economic Review 83(5), 1281-1302.

Rebonato, R. (2014). A critical assessment of libertarian paternalism. Journal of Consumer Policy 37(3), 357-396.

REN21 (2009). Renewables Global Status Report: 2009 Update. REN21 Secretariat.

Schubert, C. (2016), Green nudges: Do they work? Are they ethical?, Joint Discussion Paper Series in Economics, University of Kassel. 
Sörqvist, P., Hedblom, D., Holmgren, M., Haga, A., Langeborg, L., Nöstl, A., and Kågström, J. (2013). Who needs cream and sugar when there is eco-labeling? Taste and willingness to pay for 'eco-friendly' coffee. PloS one 8(12), e80719.

Steele, A.T. (1951). Weather's effect on the sales of a department store. Journal of Marketing $15,436-443$.

Sugden, R. (2017). Do people really want to be nudged towards healthy lifestyles?. International Review of Economics 64(2), 113-123.

Sugden, R. (2018). 'Better off, as judged by themselves': a reply to Cass Sunstein. International Review of Economics 65(1), 9-13.

Sunstein, C.R. (2015). Nudges, agency, and abstraction: A reply to critics. Review of Philosophy and Psychology 6(3), 511-529.

Sunstein, C. R. (2018). "Better off, as judged by themselves": a comment on evaluating nudges. International Review of Economics 65(1), 1-8.

Thaler, R.H. and Sunstein, C.R. (2003). Libertarian paternalism. American Economic Review $93(2), 175-179$.

Thaler, R. H. and Sunstein, C.R. (2009). Nudge: Improving decisions about health, wealth, and happiness. Penguin.

Van Doorn, J. and P.C. Verhoef (2011). "Willingness to pay for organic products: Differences between virtue and vice foods. International Journal of Research in Marketing 28(3), 167-180.

Van Loo, E.J., Caputo, V., Nayga Jr, R.M., and Verbeke, W. (2014). Consumers? valuation of sustainability labels on meat. Food Policy 49, 137-150.

Van Loo, E.J., Hoefkens, C., and Verbeke, W. (2017). Healthy, sustainable and plant-based eating: Perceived (mis) match and involvement-based consumer segments as targets for future policy. Food Policy 69, 46-57.

Weitzman, M. L. (1974). Prices vs. Quantities. The Review of Economic Studies 41(4), 477-491. 


\section{A Figures and Tables}

Figure 1: The labels during the treatment conditions in the Label (a) and the Label5 and Label10 (b) experiment.

(a)

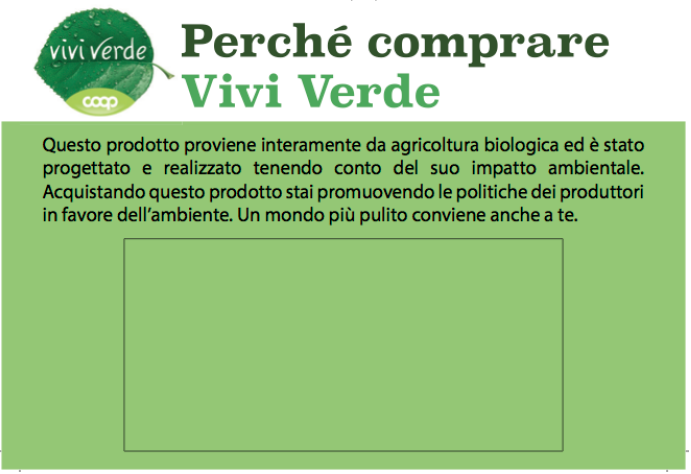

(b)

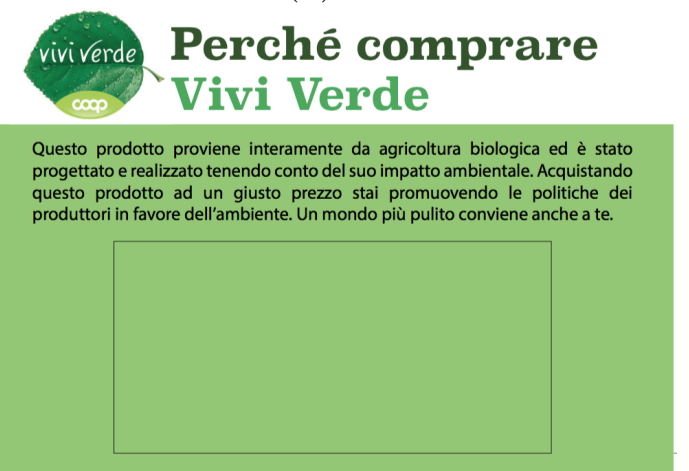

English translation: (a) Why buy Vivi Verde. This product comes from organic farming and was designed by considering its environmental impact. By purchasing this product you are supporting environmentally responsible producer policies. A cleaner world is better also for you. (b) Why buy Vivi Verde. This product comes from organic farming and was designed by considering its environmental impact. By purchasing this product at a fair price you are supporting environmentally responsible producer policies. A cleaner world is better also for you.

Figure 2: The labels on the shelves during the treatment phase.

(a)

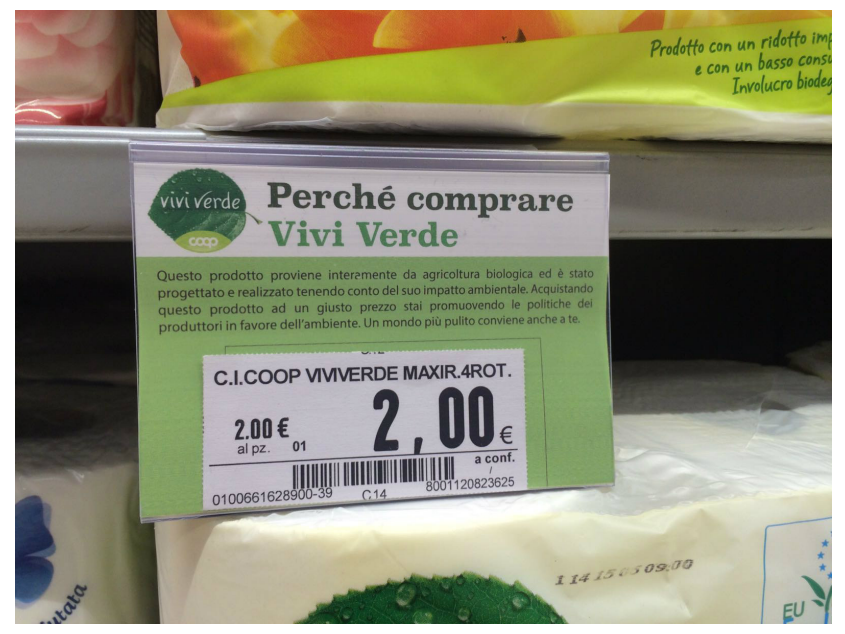

(b)

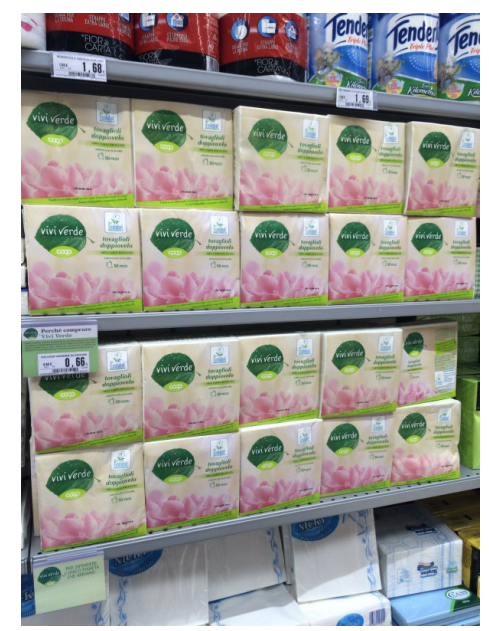


Table 1: Treatment and control phases.

\begin{tabular}{|c|c|c|c|}
\hline & & $\begin{array}{c}\text { Phase } \mathbf{1} \\
30 \text { May - 26 June }\end{array}$ & $\begin{array}{c}\text { Phase 2 } \\
27 \text { June - 24 July }\end{array}$ \\
\hline \multirow{3}{*}{ Group 1} & 2 stores & Label & Control \\
\hline & 2 stores & Label5 & Control \\
\hline & 2 stores & Label10 & Control \\
\hline \multirow{3}{*}{ Group 2} & 2 stores & Control & Label \\
\hline & 2 stores & Control & Label5 \\
\hline & 2 stores & Control & Label10 \\
\hline
\end{tabular}

Table 2: Average prices of products within selected product classes and selected Vivi Verde products.

\begin{tabular}{|c|c|c|c|c|c|c|}
\hline $\begin{array}{l}\text { Product } \\
\text { class }\end{array}$ & Obs. & Mean (SD) & Min & $\operatorname{Max}$ & Product & Price \\
\hline Teas & 5,001 & $2.12(0.967)$ & 0.64 & 9.20 & Fruit Tea, $20 \mathrm{p}$ & 1.57 \\
\hline Long-cut wheat pasta & 2,552 & $1.15(0.769)$ & 0.38 & 5.90 & Spaghetti, 500g & 0.75 \\
\hline \multirow[t]{2}{*}{ Short-cut wheat pasta } & 5,243 & $1.01(0.532)$ & 0.38 & 3.99 & Fusilli, $500 \mathrm{~g}$ & 0.75 \\
\hline & & & & & Penne, 500g & 0.75 \\
\hline \multirow{4}{*}{ Whole-wheat pasta } & 715 & $1.15(0.682)$ & 0.75 & 3.89 & Whole Wheat Spaghetti, $500 \mathrm{~g}$ & 0.75 \\
\hline & & & & & Whole Wheat Fusilli, 500g & 0.75 \\
\hline & & & & & Whole Wheat Penne, $500 \mathrm{~g}$ & 0.75 \\
\hline & & & & & Whole Wheat Ditali, 500g & 0.75 \\
\hline Bread and substitutes & 2,200 & $1.77(0.790)$ & 0.55 & 4.99 & Whole Wheat Crackers, $150 \mathrm{~g}$ & 0.66 \\
\hline Tomato preserves & 3,682 & $1.43(0.703)$ & 0.35 & 9.84 & Tomato Pulp, $690 \mathrm{~g}$ & 0.89 \\
\hline Dish detergents & 3,237 & $3.20(2.258)$ & 0.47 & 17.80 & Washing-up Liquid, 11 & 1.05 \\
\hline Big surface cleaners & 3,012 & $2.23(1.323)$ & 0.29 & 6.99 & Floor Cleaner 'Camellia', 11 & 1.35 \\
\hline Small surface cleaners & 4,857 & $2.39(1.143)$ & 0.59 & 9.8 & Glass Cleaner, $750 \mathrm{ml}$ & 1.67 \\
\hline Bin liners & 923 & $1.67(1.166)$ & 0.65 & 7.80 & Bin Liner, 151 15p & 1.95 \\
\hline Tablecloths and napkins & 938 & $1.76(1.280)$ & 0.39 & 6.99 & 2-ply Napkins, $33 \times 33 \times 50$ & 0.63 \\
\hline Disposable table covers & 1,504 & $1.93(1.235)$ & 0.49 & 5.09 & Plastic Cups 200cc no. 25 & 1.01 \\
\hline Bathroom products & 10,641 & $2.32(1.218)$ & 0.48 & 11.9 & Shower Gel, $250 \mathrm{ml}$ & 2.10 \\
\hline Toilet paper & 865 & $2.95(1.699)$ & 0.99 & 9.90 & Toilet Paper, 4 Rolls & 1.90 \\
\hline Lip protectors & 675 & $2.23(1.195)$ & 0.74 & 4.73 & Lip Balm & 1.86 \\
\hline Handkerchief & 856 & $1.75(1.257)$ & 0.47 & 7.98 & 4-Ply Paper Handkerchief, $10 \times 9$ & 0.77 \\
\hline Fruit juices & 457 & $2.27(0.804)$ & 1.59 & 3.69 & Blood Orange Juice, $750 \mathrm{ml}$ & 1.70 \\
\hline White kidney beans & 5,021 & $2.25(1.016)$ & 0.90 & 8.40 & White kidney beans, $500 \mathrm{~g}$ & 1.98 \\
\hline
\end{tabular}

Average prices of selected product classes and their Vivi Verde treated products. For each product classes the price shows the average regular retail price and standard deviation (SD) in parenthesis per unit of product. Prices of treated Vivi Verde products are expressed as of 24 March 2016. Note that Coop usually keep prices constant over the year and so did during the experiment. Observations are taken from the control phase of the experiment.

Table 3: Randomisation checks.

\begin{tabular}{lcc}
\hline & Treatment-Control & Control-Treatment \\
\hline Label Treatment & & $€ 55,642,814.83$ \\
Total Store Sales 2015 & $€ 57,082,727.11$ & 59.90 \\
Secondary Education (\% within the neighbourhood) & 60.42 & 10.75 \\
Foreigners (\% within the neighbourhood) & 9.90 & 93.20 \\
Relative Income (100 = household average) & 96.02 & \\
& & $€ 81,168,581.82$ \\
Label5 Treatment & $€ 88,618,570.12$ & 65.17
\end{tabular}


Foreigners (\% within the neighbourhood)

Relative Income $(100=$ household average $)$

Label10 Treatment

Total Store Sales 2015

Secondary Education (\% within the neighbourhood)

Foreigners (\% within the neighbourhood)

Relative Income (100 = household average $)$
16.55

99.20

15.45

99.12

$€ 70,204,034.89$
63.43
11.30
96.09

$€ 68,389,908.89$

66.77

12.30

101.78

Store sales and store neighourhood information, by control-treatment phase group and type of experiment.

Table 4: Total store sales, by treatment.

\begin{tabular}{lrrrr}
\hline & \multicolumn{2}{c}{ Total $(€)$} & \multicolumn{2}{c}{ Selected markets $(€)$} \\
Store & Control & Treatment & Control & Treatment \\
\hline Coop1 & $6,243,215$ & $5,938,517$ & 44,271 & 40,624 \\
Coop2 & $6,274,692$ & $6,213,352$ & 45,184 & 43,842 \\
Coop3 & $4,152,686$ & $4,116,991$ & 33,350 & 35,416 \\
Coop4 & $7,123,529$ & $7,184,454$ & 53,607 & 54,304 \\
Coop5 & $4,953,176$ & $5,379,769$ & 40,374 & 40,348 \\
Coop6 & $6,136,128$ & $6,768,738$ & 43,229 & 47,401 \\
Coop7 & $3,779,418$ & $3,754,279$ & 34,005 & 32,198 \\
Coop8 & $4,929,677$ & $4,839,383$ & 35,310 & 36,054 \\
Coop9 & $3,646,086$ & $3,570,964$ & 31,059 & 33,606 \\
Coop10 & $4,261,048$ & $4,144,520$ & 34,061 & 32,734 \\
Coop11 & $5,766,883$ & $5,636,025$ & 43,046 & 43,682 \\
Coop12 & $5,724,176$ & $6,007,893$ & 39,505 & 41,603 \\
Total & $6.30 \mathrm{e}+07$ & $6.36 \mathrm{e}+07$ & 477,000 & 481,812 \\
\hline
\end{tabular}

Each row shows the total sales and the sales for the selected markets during the control phase and the treatment phase in each store. The names of the stores are kept anonymous for privacy policy.

Table 5: Total Vivi Verde sales, by treatment type.

\begin{tabular}{lcrrr}
\hline \multirow{2}{*}{ Treatment type } & \multicolumn{2}{c}{ Selected product classes $(€)$} & \multicolumn{2}{c}{ Vivi Verde $(€)$} \\
Control & Treatment & Control & Treatment \\
\hline Label & 140,747 & 142,206 & 6,255 & 6,312 \\
Label5 & 184,153 & 186,011 & 8,772 & 9,297 \\
Label10 & 152,100 & 153,595 & 8,335 & 8,141 \\
Total & 477,000 & 481,812 & 23,362 & 23,749 \\
\hline
\end{tabular}

Each row shows the sales for the selected markets and the Vivi Verde sales during the control phase and the treatment phase in each treatment type.

Table 6: Total sales, by product class-treatment.

\begin{tabular}{lrrrr}
\hline & \multicolumn{3}{c}{ All products } & \multicolumn{2}{c}{ Vivi Verde products } \\
Product class & Control & Treatment & Control (\%) & Treatment (\%) \\
\hline Teas & $20,397.56$ & $20,159.76$ & $454.99(2.2)$ & $483.76(2.4)$ \\
Long-cut wheat pasta & $21,722.27$ & $22,275.90$ & $159.50(0.7)$ & $169.13(0.8)$ \\
Short-cut wheat pasta & $42,050.71$ & $43,271.55$ & $495.77(1.2)$ & $437.93(1.0)$ \\
Whole-wheat pasta & $5,966.31$ & $5,789.34$ & $2,160.74(36.2)$ & $2,110.66(36.5)$ \\
Bread and substitutes & $20,289.78$ & $19,624.06$ & $5,047.63(24.9)$ & $5,327.19(27.1)$ \\
Tomato preserves & $41,635.62$ & $41,393.00$ & $2,205.56(5.3)$ & $2,174.49(5.3)$ \\
Dish detergents & $51,315.75$ & $49,950.20$ & $1,412.29(2.8)$ & $1,418.35(2.8)$ \\
Big surface cleaners & $18,323.00$ & $17,953.29$ & $168.10(0.9)$ & $199.27(1.1)$ \\
Small surface cleaners & $36,687.92$ & $34,216.90$ & $669.64(1.8)$ & $590.21(1.7)$
\end{tabular}


Bin liners

$15,866.63$

$15,690.69$

$1,304.73(8.2)$

$1,294.41(8.2)$

Tablecloths and napkins

$15,645.79$

$15,882.90$

$1,618.08(10.3)$

$1,668.65(10.5)$

Disposable table covers

$20,764.44$

$21,909.27$

$630.33(3.0)$

$441.02(0.7)$

Toilet paper

$63,130.71$

$68,577.24$

$698.48(3.2)$

$56,161.28$

$57,496.33$

$2,532.70(4.5)$

$437.49(0.6)$

Lip protectors

$2,232.98$

$2,359.42$

$193.00(8.6)$

$2,248.16(3.9)$

Handkerchiefs

$8,720.25$

$9,006.13$

$726.01(8.3)$

$218.99(9.3)$

$4,313.36$

$4,142.09$

$624.87(14.5)$

$748.09(8.3)$

Fruit juices
White kidney beans

$31,775.82$

$32,114.05$

$2,516.58(7.9)$

$658.09(15.9)$

Each row shows total sales, Vivi Verde sales and share of Vivi Verde sales on total sales (in parenthesis) for the selected market by experimental phase.

Table 7: The treatment effect on total sales (Reduced-form analysis).

\begin{tabular}{lcccc}
\hline \multirow{2}{*}{ Variables } & Log(sales) & $\log (\mathrm{sales})$ & $\log (\mathrm{sales})$ & $\log (\mathrm{sales})$ \\
\hline \multirow{4}{*}{ VV (total) } & $0.0244^{* * *}$ & & $-0.0229^{*}$ \\
& $(0.00654)$ & & $(0.0124)$ & \\
VV Label & & 0.0197 & & $-0.0610^{* *}$ \\
& & $(0.0116)$ & & $(0.0222)$ \\
VV Label5 & & 0.0103 & & -0.00712 \\
& & $(0.00585)$ & & $(0.0133)$ \\
VV Label10 & & $0.0433^{* * *}$ & & -0.00138 \\
& & $(0.00759)$ & & $(0.0114)$ \\
Price & $-0.283^{* * *}$ & $-0.283^{* * *}$ & $-0.048^{* * *}$ & $-0.048^{* * *}$ \\
& $(0.00558)$ & $(0 . .00557)$ & $(0.00738)$ & $(0.00736)$ \\
Constant & $4.946^{* * *}$ & $4.953^{* * *}$ & $4.365^{* * *}$ & $4.357^{* * *}$ \\
& $(0.0132)$ & $(0.0118)$ & $(0.0163)$ & $(0.0210)$ \\
Store FE & Yes & Yes & Yes & Yes \\
Week FE & Yes & Yes & Yes & Yes \\
& & & & \\
Observations & 3,212 & 3,212 & 3,497 & 3,497 \\
R-squared & 0.047 & 0.047 & 0.011 & 0.012 \\
\hline
\end{tabular}

Columns Food show the effect of the treatment (total and separated by treatment) on the sales of food products in the selected markets. Columns Non-food show the effect of the treatment (total and separated by treatment) on the sales of non-food products in the selected markets. Robust standard errors clustered at store level in parentheses.

*** $\mathrm{p}<0.01,{ }^{* *} \mathrm{p}<0.05,{ }^{*} \mathrm{p}<0.1$ 


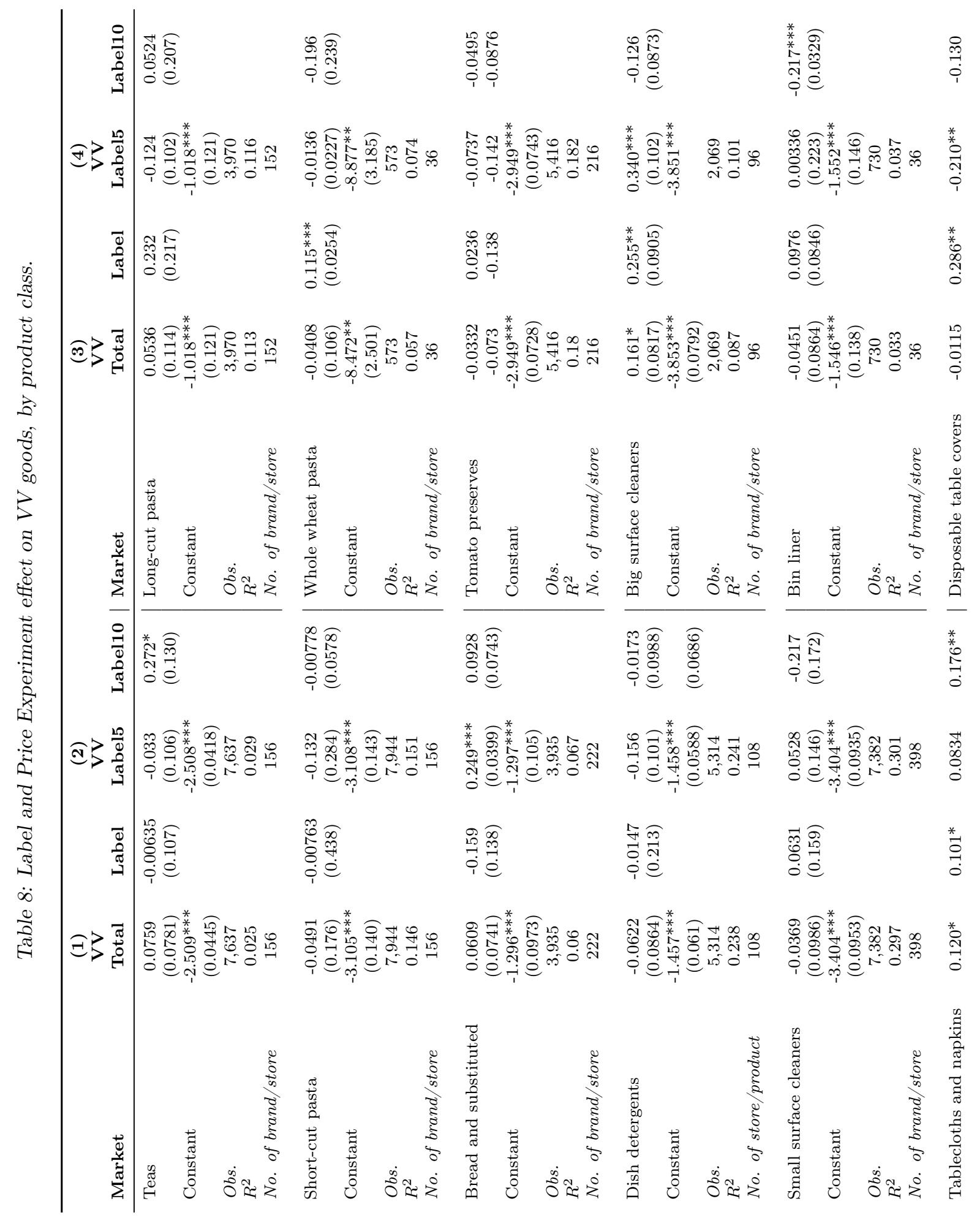




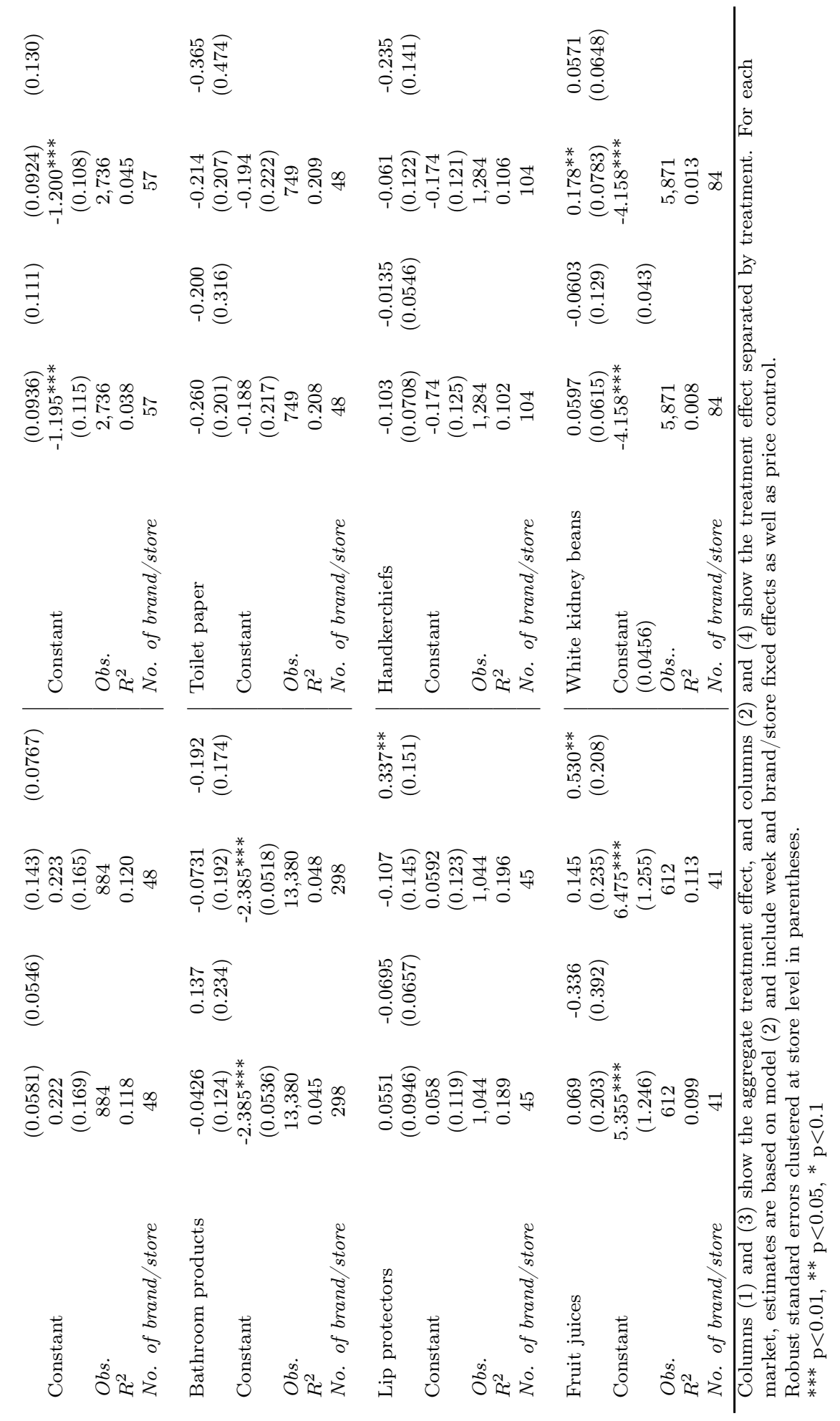


Table 9: Own Price Elasticities, by product class.

\begin{tabular}{|c|c|c|c|c|}
\hline Market & Treatment & Point estimate & Lower bound & Upper bound \\
\hline \multirow[t]{2}{*}{ Teas } & Label5 & -0.048 & -0.298 & 0.202 \\
\hline & Label10 & $0.462^{*}$ & 0.045 & 0.878 \\
\hline \multirow[t]{2}{*}{ Long-cut pasta } & Label5 & -0.088 & -0.201 & 0.024 \\
\hline & Label10 & 0.041 & -0.231 & 0.313 \\
\hline \multirow{2}{*}{ Short-cut pasta } & Label5 & -0.093 & -0.402 & 0.215 \\
\hline & Label10 & -0.006 & -0.077 & 0.065 \\
\hline \multirow[t]{2}{*}{ Whole wheat pasta } & Label5 & -0.010 & -0.038 & 0.018 \\
\hline & Label10 & -0.135 & -0.380 & 0.109 \\
\hline \multirow[t]{2}{*}{ Bread and substituted } & Label5 & $0.369 *$ & 0.259 & 0.478 \\
\hline & Label10 & 0.127 & -0.048 & 0.301 \\
\hline \multirow[t]{2}{*}{ Tomato preserves } & Label5 & -0.056 & -0.228 & 0.116 \\
\hline & Label10 & -0.038 & -0.147 & 0.070 \\
\hline \multirow[t]{2}{*}{ Dish detergents } & Label5 & $-0.182^{*}$ & -0.361 & -0.004 \\
\hline & Label10 & -0.022 & -0.223 & 0.179 \\
\hline \multirow{2}{*}{ Big surface cleaners } & Label5 & $0.570 *$ & 0.240 & 0.901 \\
\hline & Label10 & -0.167 & -0.345 & 0.011 \\
\hline \multirow{2}{*}{ Small surface cleaners } & Label5 & 0.076 & -0.280 & 0.433 \\
\hline & Label10 & -0.275 & -0.595 & 0.044 \\
\hline \multirow[t]{2}{*}{ Bin liner } & Label5 & 0.023 & -0.524 & 0.570 \\
\hline & Label10 & $-0.318^{*}$ & -0.384 & -0.252 \\
\hline \multirow[t]{2}{*}{ Tablecloths and napkins } & Label5 & 0.055 & -0.107 & 0.216 \\
\hline & Label10 & $0.121^{*}$ & 0.026 & 0.216 \\
\hline \multirow[t]{2}{*}{ Disposable table covers } & Label5 & $-0.411^{*}$ & -0.679 & -0.143 \\
\hline & Label10 & -0.265 & -0.673 & 0.144 \\
\hline \multirow[t]{2}{*}{ Bathroom products } & Label5 & -0.139 & -0.718 & 0.439 \\
\hline & Label10 & -0.345 & -0.811 & 0.121 \\
\hline \multirow[t]{2}{*}{ Toilet paper } & Label5 & -0.367 & -0.888 & 0.154 \\
\hline & Label10 & -0.582 & -1.609 & 0.446 \\
\hline \multirow[t]{2}{*}{ Lip protectors } & Label5 & -0.189 & -0.588 & 0.210 \\
\hline & Label10 & $0.745^{*}$ & 0.099 & 1.390 \\
\hline \multirow[t]{2}{*}{ Handkerchiefs } & Label5 & -0.047 & -0.196 & 0.103 \\
\hline & Label10 & $-0.166^{*}$ & -0.310 & -0.021 \\
\hline \multirow[t]{2}{*}{ Fruit juices } & Label5 & 0.266 & -0.494 & 1.026 \\
\hline & Label10 & $1.189 *$ & 0.202 & 2.174 \\
\hline \multirow[t]{2}{*}{ White kidney beans } & Label5 & $0.369^{*}$ & 0.077 & 0.661 \\
\hline & Label10 & 0.111 & -0.103 & 0.325 \\
\hline
\end{tabular}

Own price elasticities are derived from the estimated change of demand for the VV product.

Lower and upper bounds refer to the $90 \%$ confidence interval.

Table 10: The treatment effect on total sales (Group 1 Treatment-Control sequence only, last two weeks of each phase).

\begin{tabular}{|c|c|c|c|c|}
\hline \multirow[b]{2}{*}{ Variables } & \multicolumn{2}{|c|}{ Food } & \multicolumn{2}{|c|}{ Non-food } \\
\hline & Log(sales) & Log(sales) & Log(sales) & Log(sales) \\
\hline VV (total) & $\begin{array}{c}0.143^{* * *} \\
(0.0129)\end{array}$ & & $\begin{array}{c}-0.0183 \\
(0.0172)\end{array}$ & \\
\hline VV Label & & $\begin{array}{c}0.116^{* * *} \\
(0.0176)\end{array}$ & & $\begin{array}{c}-0.0431 * * * \\
(0.0102)\end{array}$ \\
\hline VV Label5 & & $\begin{array}{c}0.144^{* * *} \\
(0.0178)\end{array}$ & & $\begin{array}{l}-0.0226 \\
(0.0177)\end{array}$ \\
\hline VV Label 10 & & $\begin{array}{l}0.168^{* * *} \\
(0.00785)\end{array}$ & & $\begin{array}{l}0.00939 \\
(0.0364)\end{array}$ \\
\hline Price & $\begin{array}{c}-0.288^{* * *} \\
(0.0118)\end{array}$ & $\begin{array}{c}-0.288^{* * *} \\
(0.0118)\end{array}$ & $\begin{array}{c}-0.0527^{* * *} \\
(0.00805)\end{array}$ & $\begin{array}{c}-0.0526^{* * *} \\
(0.00807)\end{array}$ \\
\hline Store FE & Yes & Yes & Yes & Yes \\
\hline Constant & $\begin{array}{c}4.782^{* * *} \\
(0.0189)\end{array}$ & $\begin{array}{l}4.795^{* * *} \\
(0.0219)\end{array}$ & $\begin{array}{l}4.374^{* * *} \\
(0.0235)\end{array}$ & $\begin{array}{c}4.386^{* * *} \\
(0.0180)\end{array}$ \\
\hline Observations & 799 & 799 & 870 & 870 \\
\hline R-squared & 0.043 & 0.043 & 0.011 & 0.011 \\
\hline
\end{tabular}


All estimates consider stores assigned to group 1 (Treatment-Control) sequence only, observed during the last two weeks of each phase. Columns Food show the effect of the treatment (total and separated by treatment) on the sales of food products in the selected markets. Columns Non-food show the effect of the treatment (total and separated by treatment) on the sales of non-food products in the selected markets.

Robust standard errors clustered at store level in parentheses.

$* * * \mathrm{p}<0.01, * * \mathrm{p}<0.05, * \mathrm{p}<0.1$ 


\section{B The base model and imperfect information versions}

In the presence of a perception that an environmentally friendly product has a positive effect on one's own health, the positive impact of the shelf-treatment is trivially explained by self-regarding preferences. However, consider the case of products where consumer's perception of the link with health is absent.

Following Becchetti and Salustri (2019)'s vote-with-the-wallet model, the utility function for each $j$-th consumer choosing the strategy $S^{j}$ may be written as

$$
U_{j}\left(S^{j}, k\right)= \begin{cases}\frac{k+1}{n} b+a-c & \text { if } S^{j}=R \\ \frac{k}{n} b & \text { if } S^{j}=C\end{cases}
$$

where $R$ indicates the strategy of buying responsibly (i.e., changing choices after having information from the campaign poster), $C$ the strategy of buying conventionally (i.e., not changing choices after having information from the campaign poster), and $k$ represents the number of responsible co-buyers. The model, conveniently and without lack of generality, assumes that the global common good effect is multiplicative on the share of consumers making the responsible choice.

Since we are in large consumer markets, we conveniently assume that $n$ players are playing this game, with $n$ being very large and only a small subset of $n$ being represented by consumers buying in the supermarket where the poster is exposed. The area of the prisoner's dilemma for the individual consumer is defined by the following inequality

$$
\frac{1}{n} b+a<c<a+b
$$

and it is optimal to choose the responsible product only if

$$
c<\frac{1}{n} b+a
$$

The framework of our experiment is that of mass consumer markets where $n$ is very large. This implies that the first part of the LHS of the inequality gets close to zero. As a consequence, the consumer chooses the responsible product only if she has non-zero other-regarding preferences, even when the cost differential between the responsible and the conventional product (i.e., $c$ ) is small or, in formal terms, with $c>0$ and $\lim _{b \rightarrow \infty} \frac{1}{n} b=0$ inequality (B.1) holds if and only if $a>0$. It is trivial to check with perfect information on product characteristics that the area of the Prisoner's dilemma and the cooperation condition do not change with our Label treatment. Hence, the treatment should not produce a significant effect. However, we now consider the following modified version of the model where consumers are imperfectly informed of corporate environmental responsibility; therefore, the other-regarding argument entering the value of the cooperating choice is made by $a+e$, where $a$ is the deterministic component of the base model and $e$ is a normally distributed random variable with zero mean and variance $\sigma^{2}$, capturing the uncertainty of the responsible characteristics of the product. We also assume that risk-averse consumers have a standard utility function with a coefficient of risk aversion $\gamma$.

The Prisoner's dilemma condition therefore becomes

$$
\frac{1}{n} b+a\left(1-\gamma \sigma^{2}\right)<c<a\left(1-\gamma \sigma^{2}\right)+b
$$

The new pre-treatment condition for a cooperative choice is

$$
c<\frac{1}{n} b+a\left(1-\gamma \sigma^{2}\right)
$$

We now consider our Label treatment and assume that it eliminates consumers' perception of informational asymmetry on the responsible characteristics of the chosen products. We also consider that our Label treatment does not provide specific information but works on persuasion and perceptions, and we remain within the green nudging case. As a consequence, the post-treatment condition for a cooperative choice becomes

$$
c<\frac{1}{n} b+a
$$


(B.3) is slightly easier to achieve than (B.2); thus, after the treatment is introduced, some consumers may find it optimal to switch to the purchase of the green product. Additionally, according to this modified version of the base model, a significant change in the cooperative choice induced by the treatment not only implies that the treatment eliminates (or significantly reduces) the informational asymmetry but also that $a>0$ or that consumers have non-zero other-regarding preferences. Hence, the presence of otherregarding preferences is a necessary condition for the significance of the treatment under this specific version of the model.

A second modified version of the model can be considered by including the presence of a reciprocity argument where the value of the cooperative choice is a function of the number of cooperators. Reciprocity implies that players have a disutility in cooperating the larger the number of people who cooperate and vice versa (Rabin, 1993). In this second modified version, pre-treatment payoffs of the different strategies are as follows:

$$
U_{j}\left(S^{j}, k\right)= \begin{cases}\left(\frac{\mathbb{E}[j]+1}{n}\right) b+a\left(1-\gamma \sigma^{2}\right)-c+r \mathbb{E}[j] & \text { if } S^{j}=R \\ \frac{\mathbb{E}[j]}{n} b+a\left(1-\gamma \sigma^{2}\right) & \text { if } S^{j}=C\end{cases}
$$

where $r E(j)$ is the positive reciprocity effect that is a function of the number of cooperators. As a result, the pre-treatment cooperation condition becomes

$$
c<\frac{1}{n} b+a\left(1-\gamma \sigma^{2}\right)+r \mathbb{E}[j]
$$

Under this version of the model augmented with reciprocity arguments, post-treatment payoffs become

$$
U_{j}\left(S^{j}, k\right)= \begin{cases}\frac{\mathbb{E}\left[j+d_{j}(T)\right]+1}{n} b+a-c+r \mathbb{E}\left[j+d_{j}(T)\right] & \text { if } S^{j}=R \\ \frac{\mathbb{E}\left[j+d_{j}(T)\right]}{n} b+a & \text { if } S^{j}=C\end{cases}
$$

where $d_{j}(T)$ is player $j$ 's expected change in the number of cooperators because of the treatment. $d_{j}(T)$ may be different from zero either because the consumer assumes that other consumers have ex ante strong asymmetric information on product characteristics and/or that the latter assumes that other consumers have second order beliefs in the presence of a reciprocity argument.

The post-treatment cooperation condition therefore becomes

$$
c<\frac{1}{n} b+a+r \mathbb{E}\left[j+d_{j}(T)\right]
$$

with the reciprocity argument raising even more than in (B.2) the probability of shifting to the cooperative strategy after the Label treatment (again under the necessary condition of the existence of other-regarding preferences either under the form of component $A$ or of the same reciprocity argument).

To conclude, the three versions of the model (base model, augmented with asymmetric information on product characteristics, augmented with the asymmetric information on product characteristics and reciprocity effect) show that for products for which the connection with health is excluded, the Label treatment may have a positive and significant impact on the choice of the cooperative strategy (i.e.," the choice of the responsible products advertised with the shelf poster): i) only in presence of a nonzero other-regarding component combined with asymmetric information on product characteristics ii) and/or a reciprocity argument with the expectation that the shelf poster will increase the number of cooperators. The simple presence of other-regarding components without the asymmetric information and/or reciprocity argument is insufficient per se to produce a significant post-treatment effect because in that case, we are back to the base model and nothing changes after the treatment on the area of the Prisoner's dilemma and the inequality ruling the cooperation condition. Additionally, the same theoretical framework may be used to evaluate the effect of the Label5 and Label10 treatments. In such cases, we must add to the framework the impact of the change in the price difference between the conventional and the responsible product while considering the $5 \%$ or $10 \%$ increase of the latter. This effect raises (i.e., c) in the model, making the conditions for the responsible choice more difficult.

Considering what has developed, the $x_{j t}$ vector of observed good characteristics when choosing the responsible product in the Nevo (2010) specification under the base vote-with-the-wallet model (section 
4.1) includes $\frac{1}{n} b+a-c$, that is, a quantity measuring the change in utility arising when shifting from the conventional to the VV green product. This characteristic is unmodified by the experiment. If, by contrast, we are in the (second modified) asymmetric information framework, the base characteristics is $\frac{1}{n} b+a\left(1-\gamma \sigma^{2}\right)-c$ before treatment and $\frac{1}{n} b+a-c$ after treatment, with the treatment raising the utility of choosing the responsible product by $a \gamma \sigma^{2}$. Under the (third modified) asymmetric information plus reciprocity version of the model, the pre-treatment characteristic is $\frac{1}{n} b+a\left(1-\gamma \sigma^{2}\right)+r \mathbb{E}[j]-c$, and the post-treatment characteristics is $\frac{1}{n} b+a\left(1-\gamma \sigma^{2}\right)+r \mathbb{E}\left[j+d_{j}(T)\right]-c$. Hence, the treatment raises the utility of choosing the responsible product by $a \gamma \sigma^{2}+r \mathbb{E}\left[d_{j}(T)\right]$. 


\section{A survey of Coop consumers}

\section{Introduction and descriptive statistics}

To analyze in depth the motivations behind the choices that we observed in our experiment, we conducted an online survey on a sample of Coop consumers in October 2019. The sample was selected by the Coop staff among their customers (i.e., Coop loyalty card members) who agreed to be part of the online survey. The survey comprised a set of questions for each product selected in our experiment (see Table C.1 for the full list; to make the survey smoother, we excluded short-cut wheat pasta because we assumed no differences between long-cut and short-cut wheat pasta).

The number of respondents who completed the survey is 581, the majority of them were women $(60 \%)$. The age range was 19 to 87 years, with an average of 49 years. Slightly less than half were graduates (46\%), and less than that were retired people (approximately 13\%; Table C.1). These statistics demonstrate that our sample is not representative of the Italian population, which consistently differs in all of these attributes. Moreover, the level of education is not aligned with the neighborhood characteristics of our stores provided in Table 3 .

Table C.1: Descriptive statistics of the survey.

\begin{tabular}{|c|c|c|c|c|c|}
\hline \multirow[b]{2}{*}{ Variable } & \multicolumn{4}{|c|}{ Our sample } & \multirow{2}{*}{$\begin{array}{c}\text { Italian population } \\
\text { Mean }(\%)\end{array}$} \\
\hline & Mean (\%) & St. Dev. & Min. & Max. & \\
\hline Women & 59.72 & 0.491 & 0 & 1 & 51.32 \\
\hline Age (years) & 49.18 & 12.796 & 19 & 87 & 45.4 \\
\hline \multicolumn{6}{|l|}{ Education status } \\
\hline Lower secondary school & 5.9 & 0.235 & 0 & 1 & 49.25 \\
\hline Upper secondary school & 48.4 & 0.500 & 0 & 1 & 36.06 \\
\hline Higher education & 45.7 & 0.499 & 0 & 1 & 14.69 \\
\hline \multicolumn{6}{|l|}{ Job status } \\
\hline Housekeeper & 4.1 & 0.199 & 0 & 1 & \\
\hline Employee & 52.4 & 0.500 & 0 & 1 & \\
\hline Entrepreneur & 12.4 & 0.330 & 0 & 1 & \\
\hline Teacher & 5.5 & 0.229 & 0 & 1 & \\
\hline Self-employed & 11.2 & 0.316 & 0 & 1 & \\
\hline Student & 1.6 & 0.124 & 0 & 1 & 0.09 \\
\hline Retired & 12.8 & 0.334 & 0 & 1 & 26.5 \\
\hline
\end{tabular}

The survey comprised 581 Coop customers from October 2 to October 14, 2019. Italian population data were from the Italian National Institute of Statistics and are available at Istat.it.

\section{Question 1. What impact do the following environmentally friendly products have on your health? And on the health of others?}

For each product selected in our experiment, we ask respondents about the impact of that product on their health and the health of others (Figure C.1). First, we observe that the majority of respondents (approximately 60\%) consider all products positively impactful in both directions. Most of the remaining respondents (approximately 20\%) believe there are no health effects from these products and attribute no negative impact to any of them (less than $5 \%$ on average), except for shower gel (bathroom product) and plastic cup (disposable table covers), which were considered detrimental for the health of respondents and others, respectively (8\% of respondents). The remaining (approximately 15\%) are "do not know" answers. Second, and more notably, we observe that although on average the impact on respondents' health is generally higher (dashed lines), handkerchiefs, table covers, and bin liners are products whose purchase might be more important for the health of others than for the respondents. Notably, these 
products affect health only through the environmental damage from their waste. Consistently, lip protectors show an inverse result. With less difference, respondents link food products and cleaners more to their health than to the health of others, and toilet paper, dish detergent, table covers, and bathroom products are more linked to the health of others or they show no difference. These answers confirm our hypothesis that respondents who consume Vivi Verde products perceive food products as being healthier than environmentally friendly non-food products, especially for those whose consumption can be reduced.

Figure C.1: What impact do the following environmentally friendly products have on your health? And on the health of others?

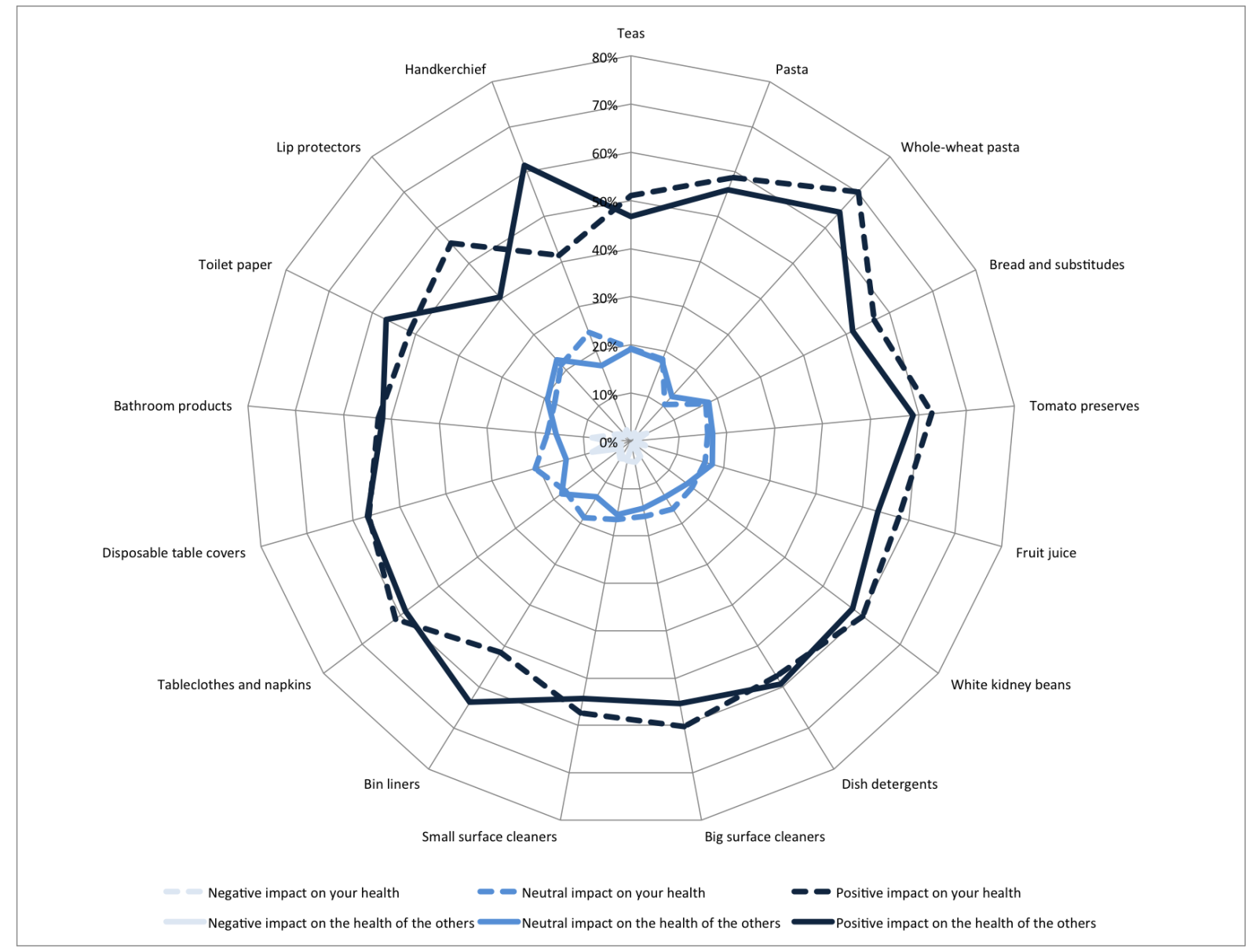

\section{Question 2. To what extent do you think that this label, if displayed on each of the following products, can induce the purchase of this product from consumers who have never bought the product?}

The question asks respondents about the impact of our label (e.g., Figure 1a) in inducing people to purchase the selected products. Figure C.2 shows that on average more than $80 \overline{\%}$ (dark and light blues) of the respondents think the label is impactful (approximately 30\% high or very high impact, approximately $30 \%$ fair impact, approximately $20 \%$ at least low impact with some variation across product classes). The products for which more respondents think the label has no effect are teas, pasta, bread and substitutes, and lip protectors, even if the difference compared with the other products is not large. We interpret these answers through two possibly relevant mechanisms. First, with organic characteristics being equal, whole wheat pasta is perceived as healthier than standard pasta and bread. Second, lip protector is the only non-food product with no well-known environmental concerns associated with excess use and waste. 
Figure C.2: To what extent do you think that this label if displayed on each of the following products can induce the purchase of this product from consumers who have never bought the product?

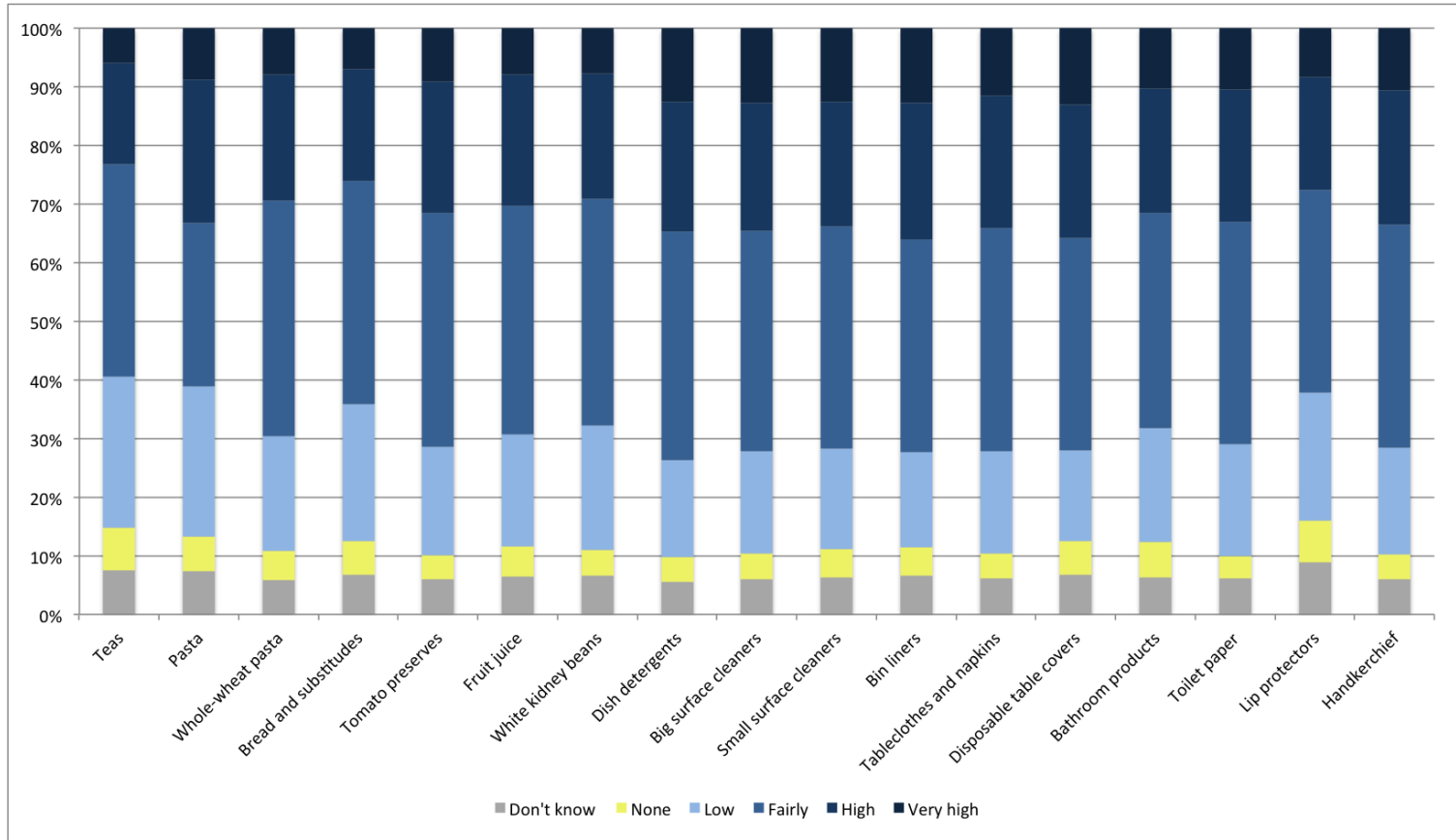

\section{Question 3. Do you volunteer for an organization? Do you participate in an environmental organization?}

Figure C.3 shows the number of respondents volunteering for an association (internal annulus) and for an environmental organization (external annulus). The majority of respondents do not volunteer for any organisation. Volunteering is more common (26\%) than environmentalism (7\%), although a few of them (10\% and $3 \%$, respectively) are involved weekly. These statistics are notably higher than the national statistics, where $1.5 \%$ of people are involved in an environmental organization and $10.5 \%$ of people are volunteer for an organization (data from the Italian National Institute of Statistics are available at Istat.it).

\section{Final Remarks}

Results from the additional survey on the perceptions of Coop loyal customers of the impact of our treatment label are in line with the interpretation of our experimental results. In particular, we observe a difference between food and non-food products in the assessment of their impact on health and the environment. As discussed in section 7, food products are generally associated with consumers' health and among food products, whole wheat pasta is the most responsive to our label. Conversely, non-food products are linked more with the environment and therefore a higher concern for the environment may also generate less consumption.

This survey has two major limitations that prevent us from closely linking it to our experiment. First, that survey was conducted three years after our experiment, when differences in economic and social conditions and environmental concerns may have affected the results. Second, the sample of loyal Coop customers who participated in the online survey is biased and may not represent the entire Coop consumer population because it shows different characteristics, for example, a higher education level and level of engagement with volunteer and environmental organizations. 
Figure C.3: Do you volunteer for an organisation? Do you participate in an environmental organization?

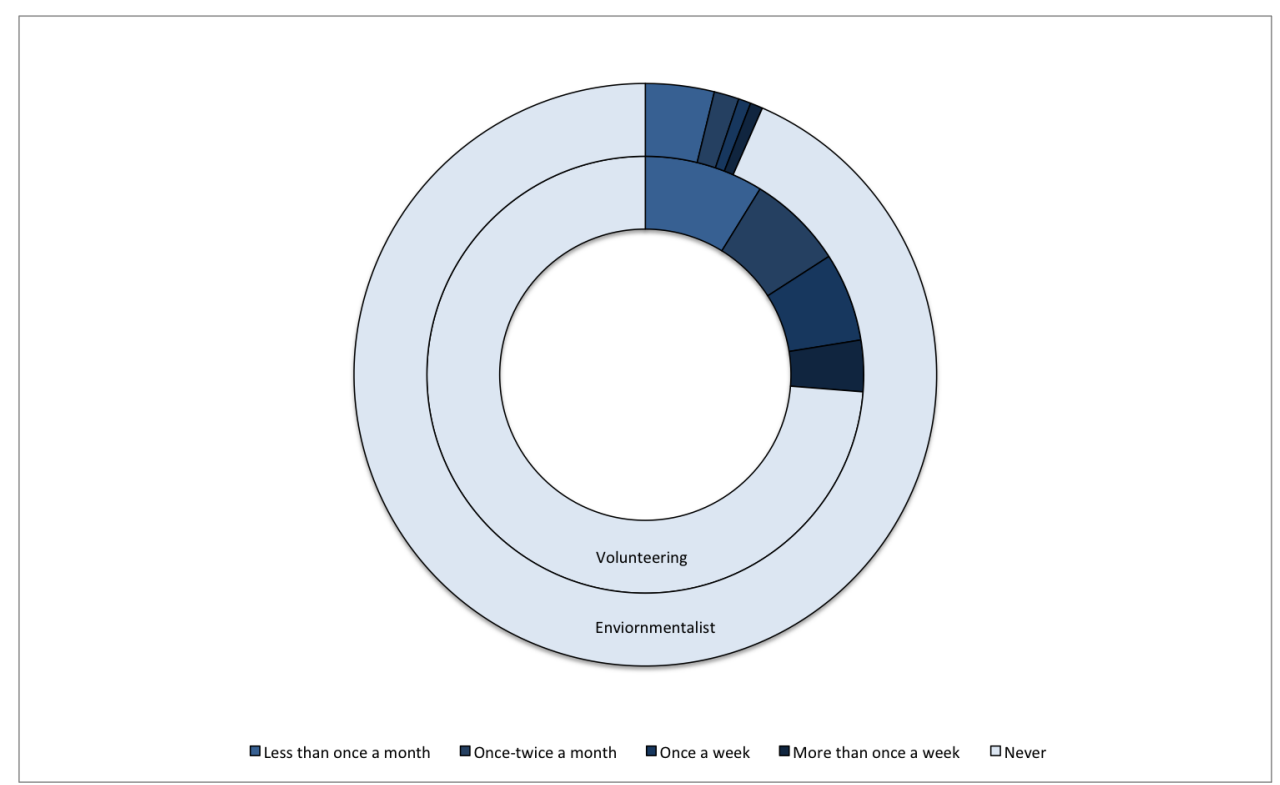

External annulus: participate in an environmental organization (Never $=93.1 \%$, Less than once per month $=3.8 \%$, Once-twice per week $=1.4 \%$, Once per week $=0.7 \%$, More than once per week $=0.7 \%$ ). Internal annulus: participate in a volunteering organization (Never $=73.7 \%$, Less than once per month $=8.8 \%$, Once-twice per week $=7.1 \%$, Once per week $=6.6 \%$, More than once per week $=3.8 \%$ ). The Italian National Institute of Statistics reports that in 2018, the share of individuals aged $14+$ years and involved in an environmental organization are $1.5 \%$, and those involved volunteering with organization are $10.5 \%$ (data are available on Istat.it). 